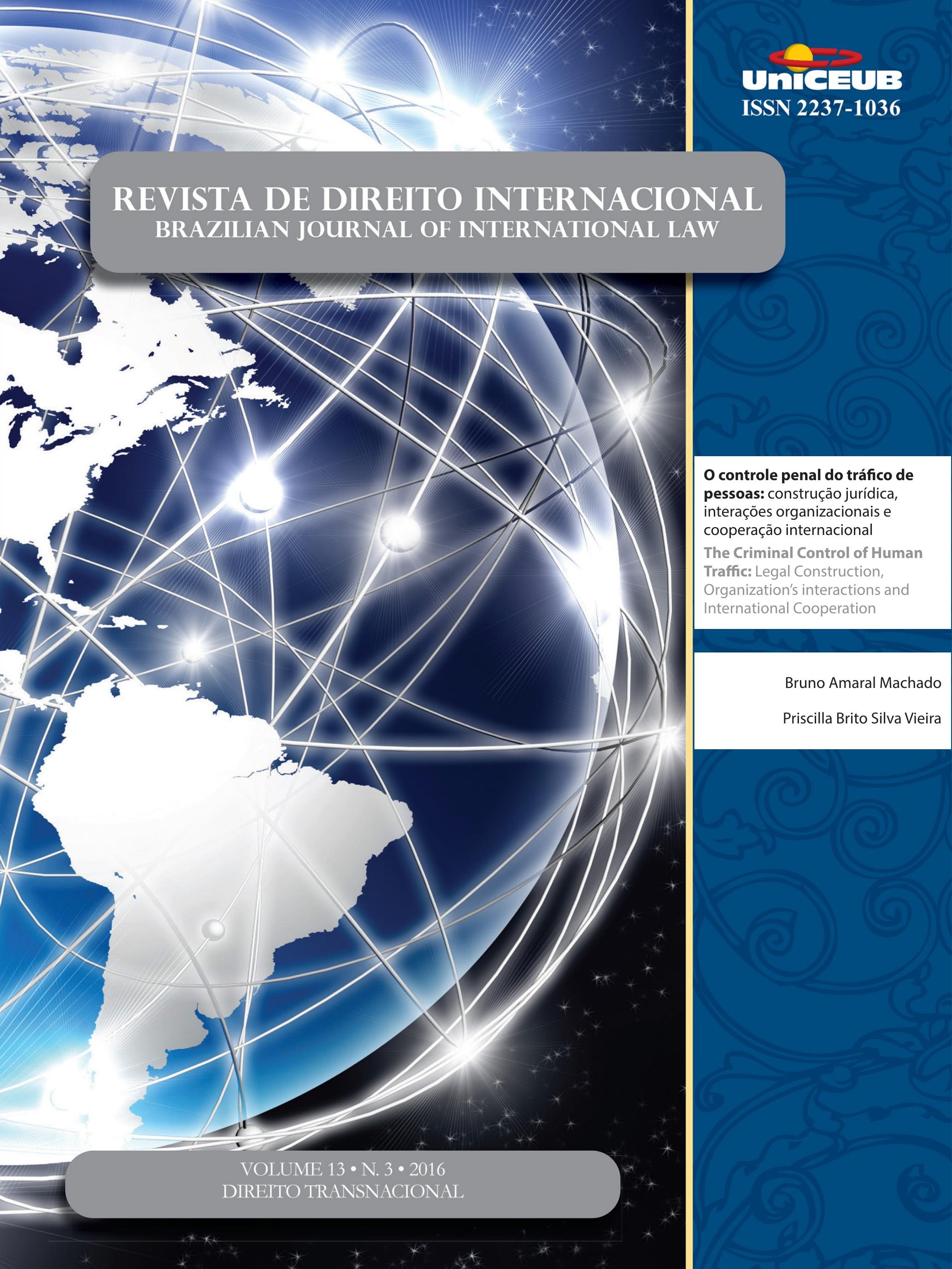


Crônicas da ATUALIdAde do direito internacional .................................................. 2

I. Dossiê Temático: Direito Transnacional .........................................................15

EDITORIAL: O Direito Transnacional - Circulação de normas e relações jurídicas transnacionais .......16 Priscila Pereira de Andrade

A emergênCia do direito transnacional ambiental .............................................18 Priscila Pereira de Andrade

Desafíos y RESPUESTAS TRANSNACIONALES FRENTE A LOS CRÍMENES AMBIENTALES ...............30 Rosmerlin Estupiñan-Silva

DiREITO TRANSNACIONAL E MUdANÇAS CLIMÁTICAS .50 Géraud de Lassus Saint-Geniès

Especies en movimiento: la Convención sobre el Comercio Internacional de Especies Amenazadas de Fauna y Flora Silvestres como espacio de “Encuentro” de discursos, ACTORES Y ESTRATEGIAS EN EL DERECHO AMBIENTAL TRASNACIONAL

María Valeria Berros e Dabel Leandro Franco

El carácter transnacional del Sistema comunitario de ECogestion « Eco-ManageMENT AND Audit SCHEME » (EMAS) DENTRo de LA UE y MÁs ALlÁ DE SUS Fronteras ......72 Adélie Pomade

O CONCEITO DE CONDUTA EMPRESARIAL RESPONSÁVEL À LUZ DOS ORDENAMENTOS JURÍDICOS BRASILEIRO, INTERNACIONAL E TRANSNACIONAL

Gabriel Webber Ziero

ARBITRAGEM NO DIREITO TRIBUTÁRIO INTERNACIONAL E NO DIREITO INTERNACIONAL DOS INVESTIMENTOS: UMA MANIFESTAÇÃO DO DIREITO TRANSNACIONAL

Vivian Daniele Rocha Gabriel 
O DIREITO TRIBUTÁRIO SOB UMA PERSPECTIVA TRANSNACIONAL

Franciele de Simas Estrela Borges

As Características do Direito Transnacional como Metodologia: Análise sob o enfoQue dos Aspectos Processuais da Arbitragem 126

Flávia Foz Mange

O DIREITO TRANSNACIONAL (“GLOBAL LAW") E A CRISE DE PARADIGMA DO ESTADO-CENTRISMO: É POSSÍVEL CONCEBER UMA ORDEM JURÍDICA TRANSNACIONAL? ...................................... 146

Luiza Nogueira Barbosa e Valesca Raizer Borges Moschen

TransPorte AÉREO E DIREITO TRANSNACIONAL: DA CONVERGÊNCIA À UNIFORMIDADE 160 Mickael R. Viglino

Outros Artigos. 175

O Fundo Monetário Internacional e a proteção dos direitos humanos: uma análise DO PROGRAMA DE CRESCIMENTO E REDUÇÃO DA POBREZA NO HAITI 177

Pablo Henrique Hubner de Lanna Costa e Carlos Alberto Simões de Tomaz

Um estranho no ninho? Padrões privados no Acordo de Barreiras Técnicas ao CoMÉRCIO DA OMC 192

Michelle Ratton Sanchez Badin e Marina Yoshimi Takitani

Os benefícios tributários do programa Inovar-Auto e os princípios da Nação Mais Favorecida e do Tratamento Nacional: uma análise dos argumentos dos Painéis atualmente em Curso contra o Brasil no Órgão de SoluÇão de Controvérsias da OMC . 211 Eric Moraes Castro e Silva

A ERA DA HUMANIDADE: REFLEXões PARA A HISTÓRIA DO DIREITO INTERNACIONAL 236 Henrique Weil Afonso

Precedentes vinculantes nos Estados Unidos da América e no direito brasileiro: Um ESTUDO COMPARADO 264

Patrícia Perrone Campos Mello 
IL DIRITTO AMBIENTALE SECONDO L'OTTICA DEL DIRITTO COSTITUZIONALE POSITIVO E LA RESPONSABILITÀ PER DANNI ALL'AMBIENTE NEL DIRITTO COMUNITARIO: LO STATO DELL'ARTE DEL DIRITTO AMBIENTALE COSTITUZIONALE E COMUNITARIO 287

Elcio Nacur Rezende

DA DESCONSIDERAÇÃo DA PERSONALIDADE JURÍDICA NAS RELAÇÕES CONSUMEIRISTAS BRASILEIRAS: ANÁLISE À LUZ DAS TEORIAS CLÁSSICAS

Daniel Amin Ferraz e Marcus Vinicius Silveira de Sá

ANALYSIS OF ADVANTAGES AND DISADVANTAGES OF FORUMS PRESCRIBED UNDER THE UNCLOS AND STATE PRACTICE: THE WAY AHEAD FOR INDIA ......................................................319

Vinai Kumar Singh

Do governo POR LEIS À governanÇA POR NúMERos: breve anÁlise do Trade in SERVICE AgreEMENT (TISA) ...............................................................................338 Jânia Maria Lopes Saldanha, Rafaela da Cruz Mello e Têmis Limberger

As DIRETIVAS EUROPEIAS COMO NORMA REGULADORA DO DIREITO ADMINISTRATIVO GLOBAL ..356 Alice Rocha da Silva e Ruth Maria Pereira dos Santos

O desenVolvimento da POlítica AGRícola COMUM dA UNião EUROPEIA 375 Tatiana de A. F. R. Cardoso Squeff

A imunidade de Jurisdição das organizaÇões internacionais FaCE AO Direito de aCESSO À JUSTIÇA 391

Fernanda Araújo Kallás e Caetano

O DIREITO INTERNACIONAL ENTRE O DEVER ÉTICO E A AÇÃo POLÍ́TICA: OS FUNDAMENTOS DE UM DEVER DE COOPERAÇÃO INTERNACIONAL NA FILOSOFIA POLÍTICA DE IMMANUEL KANT .405 Ademar Junior Pozzatti

EXTENSÃo E FRAGMENTAÇÃo NO CONTEXTO DA JURISDIÇÃO PENAL INTERNACIONAL .423 Marcus Vinícius Xavier de Oliveira

A DEFINiÇÃo JURÍdiCA DA "COMUNIDADE" .444 Nitish Monebhurrun, Michelle Lucas Cardoso Balbino, Fernanda Castelo Branco Araujo, Othon Pantoja, Míara Bogo Bruno e Cândida Dettenborn Nóbrega 
Comparative Study on Chinese Local Legislation of Science and Technology ProGRESS

LI Xiaoming e LI Yihan

O CONTROLE PENAL DO TRÁFICO DE PESSOAS: CONSTRUÇÃO JURÍDICA, INTERAÇÕES ORGANIZACIONAIS E COOPERAÇÃO INTERNACIONAL

Bruno Amaral Machado e Priscilla Brito Silva Vieira

Desativismo judicial: a extradição Battisti no Supremo Tribunal Federal .505 Francisco Rezek e Israel Paulino

A decisão norte-americana do Caso Myriad: novos paradigmas para a Proteção patenTÁRIA DO CÓDIGO GENÉTICO HUMANO E BIOTECNOLOGIA 514 José Carlos Vaz e Dias e Clarisse De La Cerda 


\section{O controle penal do tráfico de pessoas: construção jurídica, interações organizacionais e cooperação internacional*}

\section{The Criminal Control of Human Traffic: Legal Construction, Organization's interactions and International Cooperation}

\author{
Bruno Amaral Machado** \\ Priscilla Brito Silva Vieira***
}

* Autores convidados

** Professor do Programa de Mestrado e Doutorado em Direito e Políticas Públicas do Uniceub. Doutor em Direito (especialidade Sociologia Jurídico-penal pela Universidade de Barcelona). Pós-doutorado em Sociologia (UnB - Jonh Jay). Promotor de Justiça (MPDFT)

*** Mestre em Relações Internacionais pela UnB. Mestranda em Direito e Relações Internacionais pelo Uniceub. Agradecemos a leitura e comentários de Ana Luisa Rivera e Antonio H. G. Suxberger

\section{Resumo}

A partir de breve descrição da evolução histórica da criminalização do tráfico internacional de pessoas, o artigo aborda a definição de tráfico de seres humanos segundo o Protocolo de Palermo e a legislação brasileira. Sob a perspectiva organizacional, são analisados os mecanismos de controle penal e de cooperação internacional contra o tráfico de seres humanos. Algumas dificuldades foram identificadas nas interações intra e inter-organizacionais que revelam alguns dos desafios enfrentados nas políticas de combate ao tráfico internacional de pessoas. O controle penal no enfrentamento ao tráfico de pessoas é enfocado a partir das diferentes organizações que participam da divisão do trabalho jurídico-penal.

Palavras-chave: tráfico internacional de pessoas - Protocolo de Palermo controle penal - organizações - cooperação internacional

\section{Abstract}

The article begins with a brief illustration of the development of the criminalization of international trafficking in persons to discuss the definition according to Palermo Protocol and Brazilian legislation. From the organizational perspective, mechanisms of criminal control and international cooperation against human trafficking are analyzed. Difficulties identified in intra and inter-organizational interactions revealed some challenges faced by public policies against trafficking in persons. The criminal control on human trafficking is focused from the perspective of different organizations that take part in the division of criminal legal work.

Key words: international trafficking in persons - Palermo Protocol - criminal control - organizations - international cooperation 


\section{INTRODUÇÃO}

A função do direito tornou-se objeto de interesse acadêmico e político, sob forte influência do funcionalismo nas disciplinas jurídicas ${ }^{1}$. O direito penal é um dos campos onde essa influência é mais evidente. A vulgarização do conceito de controle social nas disciplinas penais, distantes da concepção original formulada pela Escola de Chicago, sugere que essa suposta função do direito penal deve ser redefinida como controle penal ${ }^{2}$. A discussão é complexa e pode ser contextualizada a partir de dois prismas, delimitados (e simplificados) neste artigo: o teórico, dogmático-penal e criminológico, e o político. O primeiro (penal e criminológico) remete à extensa literatura que recorre tradições distintas sobre as finalidades da pena e as funções do direito penal (retribuição, prevenção, reintegração social, simbolismo penal) ${ }^{3}$. O segundo está associado aos debates contemporâneos sobre os significantes políticos da intervenção penal e a permeabilidade das decisões políticas às discursividades penais e criminológicas ${ }^{4}$. Nesse sentido, o controle penal deve ser compreendido como forma peculiar de controle político exercido por meio do direito penal e das instituições incumbidas da sua imposição. Em outras palavras, o direito penal associa-se ao ideário de um pretenso "controle social punitivo".

As transformações do controle penal contemporâneo não devem estar dissociadas das grandes mudanças do cenário internacional das últimas décadas ${ }^{5}$. O pro-

1 BERGALLI, Roberto. "Control social y sistema penal". In: BERGALLI, Roberto. Control social punitivo. Sistema penal e instancias de aplicación (Policía, Jurisdicción y Cárcel). Barcelona: Bosch, 1996, pp. 1-5. 2 MELOSSI, Dario. El Estado del control social. México/DF: Siglo veintiuno, 1992. BERGALLI, Roberto. Control social punitivo. Sistema penal e instancias de aplicación (Policia, Jurisdicción y Cárcel). Barcelona: Bosch, 1996, pp. 1-5.

3 Há poucas evidências empíricas de que o direito penal tenha real dissuasório e que controle a prática de crimes. MACHADO, Bruno. Justiça criminal: diferenciação funcional, interações organizacionais e decisões. São Paulo: Marcial Pons, 2014. PIRES, A. Racionalidade penal moderna, o publico e os direitos humanos na modernidade tardia. Revista Novos Estudos do CEBR AP, $\mathrm{n}^{\circ}$ 68, 2004.

4 ANITUA, Gabriel Ignácio. História dos Pensamentos Criminológicos. Trad. Sérgio Lamarão. Rio de Janeiro: REVAN, 2007. Conferir extensa crítica às justificativas do poder punitivo e a proposta de uma "teoria agnóstica da pena". CARVALHO, Salo de. "Teoria Agnóstica da Pena: Entre os supérfluos fins e a limitação do poder punitivo". In: CARVALHO, Salo de. Crítica à Execução Penal. Rio de Janeiro: Lumen Juris, 2007. ZAFFARONI, Eugenio Raúl, et alli. Direito Penal Brasileiro. Rio de Janeiro: REVAN, 2011, p. 116 e ss).

5 Reproduzimos parte dos nossos argumentos em MACHADO, Bruno. Ministério Público: organizacões, representacões e trajetórias. Curitiba: gresso tecnológico possibilitou maior rapidez e fluidez nas comunicações, com impacto direto nas atividades humanas. Parte da literatura indica que a globalização econômica e a integração supranacional alteram o cenário do crime. Por um lado, determinadas práticas foram descriminalizadas, como as condutas que vulneram o controle das fronteiras. Por outro lado, a globalização econômica proporcionou o surgimento de novas modalidades de delitos ${ }^{6}$. As características mais importantes da criminalidade da globalização são: a organização, em empresa ou associação criminal, de pessoas estruturadas hierarquicamente ${ }^{7}$; a execução material e o resultado lesivo muitas vezes estão separados, no tempo e no espaço, da ação dos agentes que desempenham um papel importante no plano delituoso; relaciona-se a agentes poderosos, cujas ações têm grande impacto econômico, político e social. A capacidade de desestabilização de mercados e de corrupção de funcionários e de governos são alguns dos aspectos mais relevantes ${ }^{8}$.

As transformações a que fazemos referência levam ao que Capeller denomina de novo campo jurídico-penal (controle penal). O crime organizado tornou-se transnacional e os Estados foram confrontados por novos desafios e devem estabelecer mecanismos multinacionais de controle, compatíveis com um sistema criminal multinacional ${ }^{9}$. No contexto europeu, foram criados

Juruá, 2007. Ver também MACHADO, Bruno, "Discursos Criminológicos sobre o Crime e o Direito Penal: Comunicação e Diferenciação Funcional". Revista de Estudos Criminais, vol. 45, abr/jun 2012; MACHADO, Bruno Justiça Criminal e Democracia I. Coleção "Direito, Transdisciplinaridade \& Pesquisas Sociojurídicas”. São Paulo: Marcial Pons/ FESMPDFT, 2013; MACHADO, Bruno, Justiça Criminal e Democracia II. Coleção "Direito, Transdisciplinaridade \& Pesquisas Sociojurídicas". São Paulo: Marcial Pons/ FESMPDFT, 2015; e MATTHEWS, Roger. "O mito da punitividade revisitado". In: MACHADO, Bruno Amaral. Justiça Criminal e Democracia II. Coleção "Direito, Transdisciplinaridade \& Pesquisas Sociojurídicas". São Paulo: Marcial Pons/ FESMPDFT, 2015.

6 SILVA SÁNCHEZ, Jesus María. La expansión del derecho penal. Aspectos de la politica criminal en las sociedades postindustriales. $2^{\mathrm{a}}$ ed. Madrid: Civitas, 2001, pp. 85-86; CAPELLER, Wanda. "Schengen: son impact sur les acteurs locaux du contrôle". In: Droit et Société, no $42-$ 43, 1999 , pp. 266.

7 PUNCH, Maurice. Bandit. "Banks: Financial Services and Organized Crimes”. In: RYAN, Patrick e J. RUSH, George E. (eds.). Understanding Organized Crime in Global Perspective: A Reader. Thousands Oaks/London/New Delhi: Sage, 1997, p. 128. CARTER, David L. "International Organized Crime: Emerging Trends in Entrepreunerial Crime". In: RYAN, Patrick J./RUSH, George E. (Eds.), ibid, p. 147.

8 SILVA SÁNCHEZ, op. cit., p. 87.

9 CAPELLER, Wanda. "La transnationalisation du champ penal: réflexions sur les mutations du crime et du contrôle". In: Droit et Société, no 35,1997, pp. 62-65. 
organismos políticos e administrativos para defesa dos interesses comunitários. Além disso, novas práticas delituosas, consideradas transnacionais, levaram à unificação das operações de controle, à idealização de novos institutos e à proposta de texto jurídico para atender às novas necessidades (Corpus Juris) ${ }^{10}$.

O fenômeno é complexo e insere-se no contexto de ampla expansão e diversificação das formas de intervenção penal ${ }^{11}$. As expectativas sobre o potencial do direito para o controle de condutas é um dos vetores para análise dos processos de produção normativa penal. Uma das manifestações da expansão do controle penal contemporâneo relaciona-se às iniciativas transnacionais para enfrentar o tráfico de seres humanos.

O tráfico internacional de pessoas foi definido como fato típico pelo Protocolo Adicional à Convenção das Nações Unidas contra o Crime Organizado Transnacional Relativo à Prevenção, Repressão e Punição do Tráfico de Pessoas, em Especial Mulheres e Crianças - Protocolo de Palermo ${ }^{12}$. A conduta típica reúne, de forma geral, uma ação relativa à movimentação da pessoa que foi convencida, por fraude ou engano, e que, ao chegar ao país de destino, é submetida à exploração, em condições que ferem a dignidade humana.

A discussão sobre tráfico não é recente, mas a definição mais abrangente, ainda que não exaustiva, só foi alcançada no século XXI. Permeado por paixões morais e pela obscuridade dos fatos, o debate sobre a criminalização do tráfico internacional de seres humanos desvela a complexidade de se estabelecer uma definição e a dificuldade de se obter consenso internacional sobre as diversas situações e contextos em que ocorre a explora-

10 CAPELLER (1999), op. cit., p. 266; DE ANGELIS, Francesco. "Internazionalizzazione degli scambi economici ed illegalità: una sfida per l'armonizzazione delle procedure repressive". In: Questione Giustizia, no 3-4, 1992, p. 640.

11 Segundo Silva Sánchez, as possíveis causas da expansão do direito penal, em especial na última década, seriam dois grupos de fatores: fatores objetivos - como os novos interesses definidos pela doutrina como bens coletivos e difusos, o aparecimento de riscos decorrentes das novas técnicas e a institucionalização da insegurança, diluída em uma sociedade cada vez mais complexa - e fatores subjetivos, constituídos especialmente pela sensação de insegurança potencializada pela mídia e pelas próprias instituições públicas. SILVA SÁNCHEZ, op. cit., p. 87.

12 BRASIL, Decreto n ${ }^{\circ}$ 5.017, de 12 de março de 2004. Protocolo Adicional à Convenção das Nações Unidas contra o Crime Organizado Transnacional Relativo à Prevenção, Repressão e Punição do Tráfico de Pessoas, em Especial Mulheres e Crianças (Protocolo de Palermo). ção das vítimas ${ }^{13}$. Em um cenário globalizado, em que as fronteiras são virtuais e a comunicação é instantânea, os criminosos se organizam em redes internacionais ${ }^{14}$, utilizando meios legítimos, como a internet e o transporte aéreo, para aliciar, transportar e explorar vítimas. Uma vez que o iter criminis pode se dar em distintos pontos do globo terrestre, dificilmente um país conseguiria enfrentar o tráfico de maneira isolada.

Se tradicionalmente a implantação da legislação penal (Law enforcement) depende da articulação entre diferentes atores e organizações envolvidos na investigação e persecução penal, os novos desafios impostos pela criminalização de condutas transnacionais impõem também a necessidade de formas de cooperação internacional. Em outras palavras, a viabilização do controle penal supõe a cooperação internacional para enfrentar o tráfico de seres humanos ${ }^{15}$. Uma das estratégias para implantar um marco normativo geral concretiza-se por meio de tratados internacionais, com diretrizes comuns sobre a criminalização do tráfico de pessoas a serem implantadas pelos Estados, a fim de permitir o alinhamento conceitual e facilitar a cooperação internacional entre os países. A cooperação internacional enseja o cumprimento em território nacional de medidas processuais expedidas por autoridades competentes de outro país, contornando a limitação territorial imposta pelo princípio da soberania estatal que vigora no direito internacional ${ }^{16}$. A cooperação internacional pode abranger diversas medidas de intercâmbio de informações e procedimentos jurisdicionais, entre órgãos judiciais e administrativos de dois ou mais países, a fim de tornar possível a efetivação de medidas processuais no território de outro Estado. Neste sentido, seria mais preciso falar-se em cooperação jurídica internacional - e não apenas judicial ${ }^{17}$.

13 AROMAA, Kauko, "Trafficking in Human Beings: Uniform Definitions for Better Measuring and for Effective Counter-Measures". In: SAVONA, Ernesto U. \& STEFANIZZI, Sonia (eds.). Measuring Human Trafficking Complexities And Pitfalls. New York: Springer - INPAC, 2007, pp. 13-16.

14 SUZUKI, Natália, "Escravo, Nem Pensar! Uma experiência da sociedade civil para a prevenção ao tráfico de pessoas e ao trabalho escravo". In: SECRETARIA NACIONAL DE JUSTIÇA, Tráfico de Pessoas: uma abordagem para os direitos bumanos. Brasília: Ministério da Justiça, 2013, p. 179.

15 Ibid., p. 179.

16 ARAÚJO, Nádia, "A importância da cooperação jurídica internacional para a atuação do estado brasileiro no plano interno e internacional". In: Ministério da Justiça - Secretaria Nacional de Justiça, DRCI (org.). Manual de Cooperação Jurídica Internacional e Recuperação de Ativos - Matéria Penal, 4a ed. Brasília: 2013, v. 1, pp. 27-44.

17 PERLINGEIRO, Ricardo, “Cooperação Jurídica Internac- 
Em geral, a cooperação jurídica internacional se efetiva por meio de cartas rogatórias, homologação de sentença estrangeira, extradição, transferência de presos ou transferência de processos. Mais recentemente, o auxílio direto entre autoridades competentes previstas em tratados tem se tornado uma modalidade de cooperação cada vez mais frequente, pois a própria autoridade administrativa pode prestar as informações solicitadas ou encaminhar para a execução por juízo de primeiro grau, dispensando o exequatur do Superior Tribunal de Justiça - STJ. Com a internacionalização do crime organizado e a ampliação dos mecanismos de intercâmbio de informações, a cooperação jurídica internacional torna-se uma ferramenta essencial ao processo judicial ${ }^{18}$.

Nesse sentido, identifica-se a consolidação de rede internacional de autoridades públicas a fim de viabilizar a implantação da cooperação jurídica prevista nos tratados internacionais. Essa rede de organizações amplia os pontos de contato entre os diversos países e representa um atalho para a obtenção de informações necessárias ao processo penal, inclusive no combate ao tráfico de pessoas. Assim, os "diferentes laços criados entre as subunidades governamentais criam uma verdadeira rede de cooperação jurídica internacional" ${ }^{19}$. A cooperação internacional possibilita coordenar as interações entre as autoridades centrais de cada país, superar eventuais incoerências e, eventualmente, a construção de protocolos e pautas comuns ${ }^{20}$.

ional". In: TIBÚRCIO, Carmen \& BARROSO, Luís Roberto (org.). O Direito Internacional Contemporâneo. Rio de Janeiro, Renovar, 2006. Apud ARAUJO, Nádia, "A importância da cooperação jurídica internacional para a atuação do estado brasileiro no plano interno e internacional". In: Ministério da Justiça - Secretaria Nacional de Justiça, DRCI (org.), op. cit., pp. 39-50.

18 Nota-se o incremento dos atos de cooperação internacional nas áreas cível e penal. O STF analisou cerca de dez mil cartas rogatórias e sete mil sentenças estrangeiras entre 1930 e o final de 2004. O STJ passou a receber solicitações dessa natureza no início de 2005. Conforme Nádia Araújo: "O aumento exponencial dos pedidos, tanto de cartas rogatórias como de sentenças estrangeiras, denota o incremento da importância da matéria, tendo o STJ dinamizado o cumprimento desses atos, que hoje tramitam de forma célere, sempre que não forem impugnados". (...) "Em face do crescimento do crime organizado em âmbito global, com ramificações em mais de um país, o STJ passou a deferir os pedidos que contêm medidas de caráter executório na área penal. Nestes têm sido utilizadas, com frequência, as convenções internacionais multilaterais, como a das Nações Unidas de combate ao crime organizado". ARAÚJO, op. cit., p. 34-36.

19 FERREIRA, Luciano Vaz \& MOROSINI, Fábio Costa, "Transgovernamentalismo e Cooperação Jurídica Internacional no Brasil". In BAPTISTA, Luiz Olavo (coord.). Direito Internacional Contemporâneo. Curitiba: Juruá, 2014, p. 197.

20 MACHADO, Bruno. Justiça criminal: diferenciação funcional, inter-
Em anterior estudo sustentamos que a abordagem organizacional-sistêmica propicia ferramentas para análise das organizações que participam da divisão do trabalho jurídico-penal. Compreender os processos decisórios das organizações supõe investigar extenso rol de premissas decisórias. Distinguem-se, assim, os programas condicionais (definidos pelos tratados, legislações e atos normativos), dos programas finalísticos, tais como as prioridades organizacionais estabelecidas, os planos estratégicos, etc. O organograma interno, conformado pela distribuição de atribuições e hierarquia interna e as formas de recrutamento de membros também se constituem em premissas decisórias. A cultura organizacional, consistente nas rotinas cognitivas que orientam as decisões, também é relevante para mapear a forma como decidem (comunicam) as organizações ${ }^{21}$.

O objetivo deste artigo é descrever o processo de criminalização primária (tipificação dos crimes) em relação ao tráfico internacional de pessoas, assim como os mecanismos e instrumentos para atuação das diferentes organizações que participam da divisão do trabalho jurídico-penal. No modelo teórico proposto, pretende-se descrever os programas condicionais estruturados por meio de tratados e legislações. Para isso, apresenta-se breve evolução histórica da criminalização no plano internacional e no Brasil. Em seguida, o conceito de tráfico de pessoas é analisado conforme os termos estabelecidos no Protocolo de Palermo. Essa definição servirá de baliza para avaliar as condições para que as distintas organizações que participam da divisão do trabalho jurídico-penal exerçam a função de controle penal e identificar eventuais iniciativas no sentido de promover a interação organizacional, bem como os mecanismos idealizados e colocados em ação para a cooperação internacional no enfrentamento do tráfico de seres humanos.

\section{A Criminalização do Tráfico Internacional de Pessoas: Evolução HistóRICA}

$\mathrm{Na}$ análise proposta, é relevante compreender os processos de positivação internacional do direito, por meio de tratados, e sua posterior ratificação pelos Esta-

ações organizacionais e decisões. São Paulo: Marcial Pons, 2014, pp. 43-44 21 MACHADO, Bruno. Justiça criminal: diferenciação funcional, interações organizacionais e decisões. São Paulo: Marcial Pons, 2014, pp. 36-42. 
dos e mudanças nos respectivos ordenamentos jurídicos internos em relação ao tráfico internacional de pessoas. $\mathrm{Na}$ linguagem organizacional-sistêmica, o objetivo é mapear o processo de construção dos programas condicionais, premissa decisória das diferentes organizações incumbidas do controle penal ${ }^{22}$.

Os primeiros esforços contra o tráfico de pessoas começaram ainda no século XIX, com os tratados sobre a abolição da escravidão. No entanto, esses tratados não abordavam as questões relativas ao tráfico de seres humanos como é entendido hoje $\mathrm{e}^{23}$. O processo de criminalização do tráfico de pessoas deve considerar a circunstâncias sociais e culturais em que cada tratado foi firmado.

No início do século XX, foram firmados dois tratados entre países europeus para a supressão do tráfico de escravas brancas ${ }^{24}$. Naquele momento, a expressão escrava branca representava as mulheres que eram obrigadas a se prostituir em bordéis europeus e não incluía aquelas que faziam trabalhos domésticos, na sua maioria, mulheres africanas negras ${ }^{25}$. Sem dúvida era um conceito permeado pela moralidade social da época e que restringia o entendimento de tráfico de pessoas à exploração sexual da vítima.

Os referidos tratados surgem como os primeiros esforços para a cooperação jurídica internacional contra o tráfico de pessoas, a fim viabilizar a troca de informações entre países, por meio de cartas rogatórias, sobre infrações penais ou sentenças relativas ao tráfico de mulheres. Os Estados também se comprometiam a fazer refletir em seu arcabouço normativo nacional as infrações previstas nos referidos tratados ${ }^{26}$.

22 MACHADO, Bruno. Justiça criminal: diferenciação funcional, interações organizacionais e decisões. São Paulo: Marcial Pons, 2014, p. 36.

23 GALLAGHER, Anne T. The International Law of Human Trafficking. New York: Cambridge University Press, 2010, p. 55. Para Kevin Bales, "This agreed standardization aims to resolve many of the problems arising from the existence of more than 300 laws and agreements that have been written concerning first the slave trade, then trafficking, and which have defined the crime of buman trafficking in different ways". BALES, Kevin. "What Predicts Human Trafficking?", 31(2) International Journal of Comparative and Applied Criminal Justice (2007), p. 270.

24 Foram firmados o Acordo para a Repressão do Tráfico de Escravas Brancas (Convenção de 1904) e a Convenção Internacional para a Repressão do Tráfico de Mulheres Brancas (Convenção de 1910).

25 GALLAGHER, op. cit., pp. 56-57.

26 Convenção Internacional para a Repressão do Tráfico de Mulheres Brancas (Convenção de 1910). Disponível em https://treaties. un.org $/$ Pages $/$ ViewDetails.aspx?src $=$ TREATY\&mtdsg_no $=$ VII-
No âmbito da Liga das Nações foi concluída, em 1921, a Convenção Internacional para a Supressão do Tráfico de Mulheres e Crianças, que incluiu expressamente, pela primeira vez, a necessidade de se adotar medidas administrativas e legislativas de proteção a "crianças de ambos os sexos", meninos e meninas indistintamente ${ }^{27}$. Em 1933, foi firmada a Convenção Internacional para a Supressão do Tráfico de Mulheres Maiores de Idade $^{28}$, inaugurando a possibilidade de punição do autor do crime ainda que houvesse o consentimento da vítima.

No escopo das Nações Unidas, a Declaração Universal de Direitos dos Homens firmou os grandes princípios de proteção dos direitos humanos, como a dignidade da pessoa humana e a liberdade individual, inclusive para escolher um trabalho. Esses princípios norteiam a ação internacional de combate ao tráfico de pessoas e de enfrentamento contra a exploração humana.

A Convenção para a Supressão do Tráfico de Pessoas e da Exploração da Prostituição de Outrem ${ }^{29}$ trouxe importante inovação para o arcabouço normativo de combate ao tráfico de pessoas ao indicar como sujeito da proteção estatal a pessoa, independente do sexo ou da idade. A questão deixa de ser centralizada na mulher como vítima e passa a abranger homens, mulheres e crianças.

Outro avanço foi atribuir aos Estados o dever de adotar as medidas necessárias à prevenção da prostituição e à proteção de imigrantes, e garantir que os criminosos sejam julgados e punidos. Entre os diversos mecanismos de cooperação entre os Estados Membros, destacam-se a extradição, a cooperação internacional

9\&chapter $=7 \&$ lang $=$ en. Acessado em 3 de abril de 2016. art. $5^{\circ}$ ao $7^{\circ}$.

27 "The High Contracting Parties agree to take all measures to discover and prosecute persons who are engaged in the traffic in children of both sexes and who commit offences within the meaning of Article 1 of the Convention of May 4, 1910”. Grifamos. Convenção Internacional para a Supressão do Tráfico de Mulheres e Crianças (Convenção de 1921), art. $2^{\circ}$.

28 Convenção Internacional para a Supressão do Tráfico de Mulheres Maiores de Idade (Convenção de 1933). Disponível em https:// treaties.un.org $/$ Pages $/$ ViewDetails.aspx?src=TREATY\&mtdsg no=VII-5\&chapter=7\&lang=en. Acessado em 3 de abril de 2016.

29 Convenção para a Supressão do Tráfico de Pessoas e da Exploração da Prostituição de Outrem (Convenção de 1950). Disponível em https://treaties.un.org/Pages $/$ ViewDetails.aspx?src=IND\&mtdsg_ no=VII-11-a\&chapter=7\&lang=en. Acessado em 3 de abril de 2016. Assinada apenas em 1950, em Nova Iorque, o Preâmbulo da Convenção retoma todos aqueles tratados já firmados até então, mantendo-os em vigor para os Estados parte. 
em matéria penal para intercâmbio de informações e execução de demandas de autoridades estrangeiras. Ressalta-se também a importância de coordenação entre as autoridades internas e a centralização dos resultados da investigação dos crimes cometidos ${ }^{30}$.

Contudo, a prostituição continuava como a única forma de exploração associada ao tráfico de pessoas, o que espelha parte da moralidade social da época em relação às formas de exploração dos seres humanos ${ }^{31}$. A Convenção foi alvo de diversas críticas por não oferecer mecanismos adequados de proteção para as mulheres, nem respostas às violações de direitos humanos. Ainda que considerada "extremamente fraca", a referida Convenção se manteve como o marco legal de combate ao tráfico de pessoas por mais de meio século ${ }^{32}$.

A Convenção sobre a Eliminação de Todas as Formas de Discriminação contra a Mulher - CEDAW, de 1979, definiu que todos os Estados-Parte deveriam adotar as medidas necessárias a fim de suprimir todas as formas de tráfico de mulheres e exploração da prostituição ${ }^{33}$.

Por meio da Convenção sobre Direitos da Criança - CDC, de 1989, os Estados Membros se comprometeram a proteger os menores de 18 anos contra todas as formas de violência física ou mental, abuso ou exploração sexual, prostituição ou pornografia, exploração econômica e do trabalho, entre outras formas de maus tratos, além de estarem obrigados a adotar todas as medidas necessárias para impedir o sequestro, a venda ou o tráfico de crianças para qualquer finalidade ${ }^{34}$.

30 Convenção de 1950. GALLAGHER, Anne T. The International Law of Human Trafficking. New York: Cambridge University Press, 2010 , pp. 58 e 59.

31 Ao mesmo tempo em que o preâmbulo afirma que a prostituição e o tráfico de pessoas são incompatíveis com a dignidade humana, os dispositivos da Convenção não criminalizam ou proíbem a prática em si da prostituição. $\mathrm{O}$ texto busca punir apenas aqueles que aliciam e exploram as vítimas. Para Anne Gallagher, essa contradição interna da Convenção reflete a tentativa de alcançar consenso entre os Estados que condenam e aqueles que toleram a prostituição. Ibid, p. 59.

32 GALLAGHER, Anne T. The International Law of Human Trafficking. New York: Cambridge University Press, 2010, p. 62.

33 BRASIL, Decreto no 4.377, de 13 de setembro de 2002. Convenção sobre a Eliminação de Todas as Formas de Discriminação contra a Mulher (CEDAW), art. $6^{\circ}$.

34 BRASIL, Decreto no 99.710, de 21 de novembro de 1990. Convenção sobre os Direitos da Criança (CDC), art. 19, 32, 34 e 35.

\section{O Protocolo de Palermo e a Definição de Tráfico de Seres Humanos}

Nos últimos anos, o crime de tráfico internacional de seres humanos retornou à agenda internacional. A Assembleia Geral das Nações Unidas aprovou, em 2000, o Protocolo Adicional à Convenção das Nações Unidas contra o Crime Organizado Transnacional Relativo à Prevenção, Repressão e Punição do Tráfico de Pessoas, em Especial Mulheres e Crianças - Protocolo de Palermo. Esse documento representou conquista da comunidade internacional no sentido de estabelecer uma definição padronizada ${ }^{35}$, ainda que não exaustiva ${ }^{36}$, do tráfico de seres humanos ${ }^{37}$.

Apesar de não ser possível falar em conceito único, uma definição minimamente comum se faz necessária para iniciar a análise sobre os mecanismos de cooperação internacional em matéria penal ${ }^{38}$. Divergências sobre institutos jurídicos podem dificultar a cooperação, além de inviabilizar a produção e a comparação de informações sobre o tráfico ${ }^{39}$.

A definição de tráfico internacional de seres humanos é bastante complexa, pois pode abranger várias condutas criminosas, perpetradas por diferentes atores em diferentes países. A começar pelo lugar geográfico do crime, o tráfico internacional ou transnacional (termo

35 BALES, Kevin, "What Predicts Human Trafficking?", 31(2) International Journal of Comparative and Applied Criminal Justice (2007), p. 270.

36 KOTISWARAN, Prabha, "Protocol at the Crossroads: Rethinking anti-trafficking law from an Indian labour law perspective", 4 Anti-Trafficking Review (2015), p. 41.

37 "The Trafficking in Persons Protocol indicated that the above-mentioned forms of exploitation should be considered, at a minimum, in national buman trafficking legislation. By introducing the term "at a minimum" in the definition of the purposes of trafficking, Member States left open the option of including other or more specific purposes for which buman trafficking was committed. In recent years, national legislation and jurisdictions have expanded the application of trafficking legislation. This has resulted in the inclusion of phenomena that existed and forced marriages, among other things. Some countries reported cases of trafficking for the trading of body parts for rituals and/ or traditional bealing and medicine". UNODC, Global Report on Trafficking in Persons 2012. New York: UN Publication, 2012, p. 35.

38 BALES, Kevin, "What Predicts Human Trafficking?", 31(2) International Journal of Comparative and Applied Criminal Justice (2007), p. 271.

39 Sobre a importância da definição para a produção de dados confiáveis e para a elaboração de estudos estatísticos sobre o tráfico de pessoas, ver AROMAA, Kauko, "Trafficking in Human Beings: Uniform Definitions for Better Measuring and for Effective Counter-Measures". In SAVONA Ernesto U. \& STEFANIZZI, Sonia (eds.). Measuring Human Trafficking Complexities And Pitfalls, New York: Springer - INPAC, 2007, 2007, p. 15. 
usado no Protocolo) é aquele que ocorre em pelo menos dois países, ultrapassando as fronteiras nacionais. Apesar de existir também o tráfico interno de pessoas, principalmente em países com dimensões continentais como o Brasil e os Estados Unidos, este não será objeto de análise deste trabalho.

A conduta criminosa é assim definida pelo Protocolo:

\begin{abstract}
"a expressão "tráfico de pessoas" significa o recrutamento, o transporte, a transferência, o alojamento ou o acolhimento de pessoas, recorrendo à ameaça ou uso da força ou a outras formas de coação, ao rapto, à fraude, ao engano, ao abuso de autoridade ou à situação de vulnerabilidade ou à entrega ou aceitação de pagamentos ou benefícios para obter o consentimento de uma pessoa que tenha autoridade sobre outra para fins de exploração. A exploração incluirá, no mínimo, a exploração da prostituição de outrem ou outras formas de exploração sexual, o trabalho ou serviços forçados, escravatura ou práticas similares à escravatura, à servidão ou à remoção de órgãos". (Protocolo de Palermo, art. $3^{\circ}$ )
\end{abstract}

Cabe aos Estados adotar as medidas legislativas necessárias a fim de criminalizar os atos descritos acima, quando praticados intencionalmente, seja de forma tentada ou mesmo que o autor do crime seja cúmplice ou mandante, observando os conceitos fundamentais de cada sistema jurídico ${ }^{40}$.

Cada uma daquelas condutas pode ser tipificada de forma distinta em cada país. Segundo o Relatório do Escritório das Nações Unidas sobre Drogas e Crime - UNODC, a intenção foi deixar margem para que os Estados pudessem adaptar os crimes previstos no Protocolo à legislação nacional ${ }^{41}$. $\mathrm{O}$ mesmo foi pensando em relação à expressão "no mínimo" da definição de finalidade da exploração. Deixou-se, para os Estados Membros, a possibilidade de incluir outras formas de exploração ${ }^{42}$.

Em geral, a literatura divide a definição do artigo $3^{\circ}$ em três elementos: ações: recrutamento, transporte, transferência, alojamento ou acolhimento de pessoas; meios ou formas de exercício de poder: ameaça ou uso

40 BRASIL, Decreto n ${ }^{\circ}$ 5.017, de 12 de março de 2004. Protocolo Adicional à Convenção das Nações Unidas contra o Crime Organizado Transnacional Relativo à Prevenção, Repressão e Punição do Tráfico de Pessoas, em Especial Mulheres e Crianças (Protocolo de Palermo), art. $4^{\circ}$.

41 UNODC, Global Report on Trafficking in Persons 2014. New York: UN Publication, 2014, p. 16.

42 UNODC, Global Report on Trafficking in Persons 2012. New York: UN Publication, 2012, p. 35. da força ou outras formas de coação, sequestro ou cárcere privado, fraude, engano, abuso de autoridade ou da situação de vulnerabilidade, entrega ou aceitação de pagamentos ou benefícios para obter o consentimento de uma pessoa que tenha autoridade; finalidade da exploração: exploração sexual, trabalhos forçados, servidão ou remoção de órgãos, entre outras. ${ }^{43}$

Recentes estudos indicam a diversificação do campo do tráfico de pessoas, como o tráfico de óvulos para fecundação in vitro, tráfico de mulheres para servirem de barriga de aluguel ou para o casamento forçado, o tráfico de crianças para a adoção internacional ou para a participação em conflitos armados e o tráfico de pessoas portadoras de deficiência para a exploração como pedintes $^{44}$. Esse tipo de estudo reforça a complexidade do tráfico de pessoas e mostra como tem ampliado o alcance e diversificado as formas de exploração das vítimas.

Importante ressaltar, em relação à autoria no tráfico de pessoas, que o Protocolo de Palermo restringe a atividade criminosa a grandes grupos organizados transnacionais. $\mathrm{O}$ tráfico de pessoas é viabilizado por uma ampla rede de criminosos, como aliciadores e falsificadores de documentos, e profissionais, como agentes de viagem, pessoal da imigração e guarda de fronteira, policiais, entre outros. Todos colaboram para viabilizar o trânsito da vítima e a manutenção da situação de exploração.

Parte da literatura alerta para a restrição existente no Protocolo a infrações perpetradas apenas por grupos criminosos organizados e somente aquelas de natureza transnacional ${ }^{45}$. Critica-se também que esta de-

43 GALLAGHER, Anne T., The International Law of Human Trafficking. New York, Cambridge University Press, 2010, p. 29. ANJOS, F.A. dos e ABRÃO, P., "Enfrentamento ao Tráfico de Pessoas no Brasil: perspectivas e desafios". In: ANJOS, F.A. dos et al., Tráfico de pessoas: uma abordagem para direitos humanos. Brasília: Secretaria Nacional de Justiça, Ministério da Justiça, 2013, p. 219. UN.GIFT, “020 Workshop: Corruption and Human Trafficking: The Grease that Facilitates the Crime". The Vienna Forum to fight against Human Trafficking. Background Paper. Viena, 2008, p. 2. BALES, Kevin, "What Predicts Human Trafficking?", 31(2) International Journal of Comparative and Applied Criminal Justice (2007), p. 271.

44 GALLAGHER, op. cit., p. 37. CHILEA, D. \& ENACHE, A.G., "Nouvelles Formes de la Traite des Ettres Humain", 2(45) Curentul Juridic (2011), pp. 55-70. PIPER, Nicola. "A Problem by a Different Name? A Review of Research on Trafficking in South-East Asia and Oceania”, vol. 43 (1/2) International Migration (2005), p. 208.

45 BALES, op. cit., p. 271. Segundo o Protocolo de Palermo, art. $4^{\circ}$ : "O presente Protocolo aplicar-se-á, salvo disposição em contrário, à prevenção, investigação e repressão das infrações estabelecidas em 
finição não discute o problema, sob uma perspectiva local, das mulheres que são exploradas sexualmente e, mesmo, para englobar outros grupos que também são alvo do tráfico de pessoas, como homens, travestis e transexual ${ }^{46}$. No entanto, não há dados confiáveis sobre o tráfico de seres humanos. Acredita-se que um número significativo de homens sejam vítimas de tráfico de pessoas para a exploração do trabalho ${ }^{47}$. É necessário ampliar os estudos sobre a questão, a fim de conhecer as dimensões do tráfico de seres humanos e elaborar políticas públicas mais eficazes, inclusive (mas não unicamente), por meio do controle penal.

\section{Mecanismos de Controle Penal do Tráfico de Pessoas: Interações Organizacionais e os Desafios da CoOperação InTERnACIONAL}

$\mathrm{Na}$ abordagem organizacional-sistêmica as interações são relevantes para compreender as decisões organizacionais ${ }^{48}$. Se as organizações devem ser descritas como sistemas sociais autopoiéticos, as interações intra e interorganizacionais possibilitam superar eventuais incoerências e, eventualmente, a construção de protocolos e pautas comuns ${ }^{49}$.

O Protocolo de Palermo define como objetivos a prevenção e o combate ao tráfico de pessoas, bem como a proteção das vítimas. Para atingir essas metas prescreve-se a necessidade de aprimorar mecanismos de

conformidade com o Artigo 5 do presente Protocolo, quando essas infrações forem de natureza transnacional e envolverem grupo criminoso organizado, bem como à proteção das vítimas dessas infrações". Grifamos.

46 HUSSEIN, Rihab A. "The existing tensions in the defining of human trafficking at a UK and international level: a critical overview", 39(2) International Journal of Comparative and Applied Criminal Justice (2015), p. 130.

47 HUSSEIN, op. cit., p. 136.

48 Seidl propõe a seguinte tipologia: interações decisórias; interações preparatórias; interações informais com alguma relevância para a tomada de decisões; interações sem qualquer relação com o processo decisório. SEIDL, David. "Organization and Interaction". In: SEIDL, David \& BECKER, Kai Helge (ed.). Niklas Lubmann and Organizational Studies. Kristianstad: Kristianstad Boktruyckeri AB, 2005, pp. 145-150. As três primeiras formas de interação são organizacionais, pois orientadas não apenas por estruturas interativas (encontro entre as pessoas) mas também organizacionais.

49 MACHADO, Bruno. Justiça criminal: diferenciação funcional, interações organizacionais e decisões. São Paulo: Marcial Pons, 2014, pp. 43-44. interação organizacional, por meio da cooperação entre as organizações dos diferentes Estados signatários ${ }^{50}$. Dada a complexidade do crime de tráfico de pessoas, muitas vezes a investigação e o julgamento dos processos requerem esforços de diferentes jurisdições, a fim de coletar provas, sequestrar os bens obtidos por meio de atividade ilícita e prender os condenados.

A possibilidade de exercício do controle penal transnacional supõe tarefas prévias. De início, é imprescindível que os Estados criminalizem as condutas relativas ao tráfico de pessoas e, para viabilizar mecanismos de cooperação internacional, que exista ao menos uma similitude na definição do tipo penal do tráfico de seres humanos nos diferentes ordenamentos jurídicos. Para alguns autores, é essencial a existência de um arcabouço normativo como fundamento para uma resposta adequada e apropriada do sistema de justiça penal. Para isso, a legislação nacional deve contemplar também os crimes conexos ao tráfico de pessoas como, por exemplo, a lavagem de dinheiro, a corrupção, o crime organizado, além das formas de exploração como o trabalho forçado, o trabalho infantil, o casamento forçado, a dívida servil, que facilitam a investigação e a persecução penal $^{51}$.

Estas medidas promovem a cooperação internacional, pois a falta de uniformidade entre as tipificações de diferentes países pode representar sérios obstáculos à cooperação internacional ${ }^{52}$. Mesmo com a previsão do Tratado de Palermo sobre a possibilidade de assistência sem a respectiva criminalização no arcabouço jurídico nacional, os Estados podem recusar a cooperação jurídica quando não houver a dupla incriminação $0^{53}$.

Para o sucesso da investigação e do julgamento dos acusados, a cooperação entre Estados se faz necessária a fim de permitir a busca de evidências localizadas em outro país que não aquele onde se processa a ação ${ }^{54}$.

50 Protocolo de Palermo, art. $2^{\circ}$.

51 GALLAGHER, Anne T. \& HOLMES, P., "Developing an Effective Criminal Justice Response to Human Trafficking. Lessons From the Front Line". 18(3) International Criminal Justice Review, 2008, p. 321-322. Ver UNGA, A/RES/64/293, United Nations Global Plan of Action to Combat Trafficking in Persons, 12 August 2010, p. 11, \48.

52 AROMAA, Kauko, "Trafficking in Human Beings: Uniform Definitions for Better Measuring and for Effective Counter-Measures". In: SAVONA, Ernesto U. \& STEFANIZZI, Sonia (eds.). Measuring Human Trafficking Complexities And Pitfalls. New York: Springer - INPAC, 2007, p. 16.

53 BRASIL, Decreto no 5.015, de 12 de março de 2004. Convenção das Nações Unidas contra o Crime Organizado Transnacional, art. 18.

54 GALLAGHER, op. cit., p. 410. 
Em geral, quando a produção de evidências envolve as autoridades locais, utiliza-se o mecanismo de assistência jurídica mútua, que pode permitir:

\begin{abstract}
"Recolher testemunhos ou depoimentos; notificar atos judiciais; efetuar buscas, apreensões e embargos; examinar objetos e locais; fornecer informações, elementos de prova e pareceres de peritos; fornecer originais ou cópias certificadas de documentos e processos pertinentes, incluindo documentos administrativos, bancários, financeiros ou comerciais e documentos de empresas; identificar ou localizar os produtos do crime, bens, instrumentos ou outros elementos para fins probatórios; facilitar o comparecimento voluntário de pessoas no Estado Parte requerente; prestar qualquer outro tipo de assistência compatível com o direito interno do Estado Parte requerido" 55 .
\end{abstract}

Essas medidas devem se orientar pela garantia de manutenção dos direitos humanos de todos os envolvidos, sendo facultado ao Estado requerente negar a cooperação quando entender que o pedido "não respeita direitos básicos e garantias processuais contidas nos principais instrumentos de direitos humanos como a Declaração Universal de Direitos Humanos e a Convenção Internacional de Direitos Civis e Políticos" ${ }^{156}$.

Os mecanismos de interação organizacional não se restringem ao âmbito internacional. A fim de reforçar o enfrentamento do tráfico de pessoas, os Estados são estimulados a promover a coordenação nacional entre as organizações incumbidas da prevenção, investigação, persecução penal e julgamento dos crimes de tráfico de pessoas, bem como o apoio a pesquisas, campanhas de informação para as pessoas vulneráveis e para os profissionais envolvidos na luta contra o tráfico de pessoas, desenvolvimento de parcerias com organizações não-governamentais e representantes da sociedade civil envolvidos na prevenção e proteção das vítimas do tráfico de pessoas. ${ }^{57}$

Entre as frentes de pesquisa nos casos de tráfico de pessoas, deve-se investir no monitoramento da atuação institucional a fim de construir indicadores para avaliar os processos decisórios dos formuladores de política pública, da polícia, do Ministério Público e do judiciário. A construção de um banco de dados sobre o perfil das vítimas, bem como de instrumentos para monitorar

55 Decreto no 5.015, 2004, art. 18.

56 GALLAGHER, Anne T., The International Law of Human Trafficking. New York, Cambridge University Press, 2010, p. 412.

57 Protocolo de Palermo, art. 9. UNGA, Resolution 64/293, \53, p. 11. as ações de proteção oferecidas permitiriam identificar as lacunas das políticas de proteção e as respostas para atender às necessidades das vítimas ${ }^{58}$.

As pesquisas sobre a atuação das organizações que participam da divisão do trabalho jurídico-penal sugerem pistas para compreender eventuais entraves e boas práticas $^{59}$. Em pesquisa qualitativa com base em entrevistas com membros de distintas organizações do sistema criminal dos Estados Unidos, foram detectados alguns dos desafios no combate ao tráfico ${ }^{60}$. Apontou-se o desconhecimento, por parte dos operadores do direito, inclusive juízes, em relação aos instrumentos normativos que criminalizam o tráfico internacional de pessoas naquele país e que eles identificam as causas que tratam de tráfico de pessoas como de menor relevância. A pesquisa verificou também a existência de conflitos interorganizacionais. Os promotores e policiais norte-americanos divergem sobre a competência (estadual ou federal) para investigar o tráfico de pessoas e sobre a própria tipicidade dos fatos. Os autores do estudo criticaram os processos decisórios do Ministério Público, indicando que os promotores de justiça orientam seus esforços e a proposição das denúncias conforme suas expectativas de êxito processual e maior probabilidade de condenação do denunciado ${ }^{61}$.

Estudo realizado na última década indicou que, devido às dificuldades para se obter provas que configurem crime de tráfico de pessoas, a Polícia e o Ministério Público preferem enquadrar o fato como contrabando de pessoas ou migração ilegal, possibilitando a deportação da vítima e a rápida conclusão do caso $^{62}$. Quan-

58 KANGASPUNTA, Kristiina, Collecting Data on Human Trafficking: Availability, Reliability and Comparability of Trafficking Data, in SAVONA, Ernesto U. \& STEFANIZZI, Sonia (eds.). Measuring Human Trafficking Complexities And Pitfalls, New York: Springer - INPAC, p. 34.

59 MACHADO, Bruno. Justiça criminal: diferenciação funcional, interações organizacionais e decisões. São Paulo: Marcial Pons, 2014.

60 FARRELL, Amy, OWENS, Colleen \& McDEVITT, Jack. "New laws but few cases: understanding the challenges to the investigation and prosecution of human trafficking cases". 61 Crime Law Social Change (2014), pp. 139-168.

61 FARRELL, Amy, OWENS, Colleen \& McDEVITT, Jack. "New laws but few cases: understanding the challenges to the investigation and prosecution of human trafficking cases". 61 Crime Law Social Change (2014), p. 143.

62 KANGASPUNTA, Kristiina, Collecting Data on Human Trafficking: Availability, Reliability and Comparability of Trafficking Data, in SAVONA, Ernesto U. \& STEFANIZZI, Sonia (eds.). Measuring Human Trafficking Complexities And Pitfalls, New York: Springer - INPAC, p. 28. 
do as vítimas se encontram em situação ilegal no país, não raramente as organizações do sistema de justiça envolvidas na prevenção e persecução criminal se concentram apenas no aspecto migratório, a fim de promover a deportação da vítima, sem especial interesse sobre a exploração sofrida. Nesse momento, a vítima que foi explorada e teve seus direitos fundamentais violados, ao invés de protegida é criminalizada. $\mathrm{O}$ estudo revelou também que a polícia possui mecanismos organizacionais na eleição de prioridades de investigação, conforme supostas expectativas do público. Nesse sentido, os policiais dedicam mais tempo à investigação de crimes com mais visibilidade e negligenciam crimes como o tráfico de pessoas. Da mesma forma, como os promotores são mais resistentes a dar prosseguimento aos casos envolvendo o tráfico de pessoas, os policiais preferem concentrar seus esforços na investigação de crimes que terão mais probabilidade de serem encampados pelo Ministério Público ${ }^{63}$.

Outra manifestação do conflito institucional que afeta a investigação de casos relativos ao tráfico de pessoas se dá entre a polícia e as agências federais do trabalho dos Estados Unidos. No caso de tráfico de pessoas para a exploração do trabalho, a polícia indica que a responsabilidade seria das agências reguladoras. No entanto, essas instituições não possuem competência para conduzir investigações criminais. Assim, o número de casos relacionados à exploração sexual é muitas vezes superior ao de exploração do trabalho ${ }^{64}$.

Além disso, quando o olhar se volta apenas para a exploração da vítima, a análise de viabilidade da persecução penal constitui-se em fator crucial para compreender os processos decisórios. O Ministério Público norte-americano é criticado por tender a classificar as condutas como crimes comuns, como estupro, prostituição (que é crime em alguns estados dos Estados Unidos), fraude ou sequestro, de mais fácil obtenção de prova para condenações ${ }^{65}$. No entanto, a cadeia do tráfico internacional de pessoas excede, e muito, a exploração sexual. Outras práticas delituosas são praticadas por agentes que continuam ativos na rede de tráfico. O caminho mais rápido para a condenação e finalização do

63 Farrell, Owens \& McDevitt, op. cit., p. 154-155.

64 Ibid, p. 162.

65 FARRELL, Amy, OWENS, Colleen \& McDEVITT, Jack. "New laws but few cases: understanding the challenges to the investigation and prosecution of human trafficking cases". 61 Crime Law Social Change (2014), p. 141-142. processo pela promotoria pode representar a manutenção da atividade criminosa e da exploração das vítimas.

Estudos apontam que a criação de unidades organizacionais especializadas no combate ao tráfico de pessoas, com competências investigativas e processuais bem definidas, é essencial para ampliar a eficiência da investigação. A centralização permite a supervisão de todas as investigações em curso no país, com autonomia para garantir a resposta efetiva ao tráfico de pessoas, utilizando procedimentos padronizados e técnicas adequadas às especificidades e ao dinamismo do crime. Ademais, o tratamento da questão por unidades especializadas permite o controle em relação a agentes corruptos que podem mascarar situações de tráfico visando benefícios individuais ${ }^{66}$.

Essas unidades especializadas podem facilitar também a visão integrada da cooperação entre os países e a colaboração operacional no combate ao tráfico de seres humanos. A identificação de pessoas e áreas que servirão de ponto focal torna mais ágil a comunicação e permite o intercâmbio de informações sobre redes transnacionais de tráfico. É possível realizar operações conjuntas entre órgãos de diferentes países para resgatar vítimas, prender traficantes e produzir provas para a instrução processual. A cooperação internacional é, então, viabilizada pela troca de informações entre autoridades centrais sobre investigações em curso, assim como na condução de operações envolvendo mais de um país. Essas ações permitem o rastreamento de diversos pontos da cadeia do tráfico internacional de pessoas, não restringindo os resultados da operação aos limites territoriais em que determinada jurisdição atua. Forças-tarefas na Europa e na Ásia, envolvendo inclusive Ministérios Públicos e agentes da área financeira, têm obtido sucesso no enfrentamento internacional ao tráfico de pessoas. ${ }^{67}$

Dessa forma, os mecanismos de cooperação jurídica internacional ampliam a comunicação entre diferentes organizações dos Estados e fortalecem o papel de cada instituição, independente da autorização de terceiros para atuação no processo de cooperação. Contudo, a pesquisa revelou que a interação entre os diferentes

66 GALLAGHER, Anne T. \& HOLMES, P., "Developing an Effective Criminal Justice Response to Human Trafficking. Lessons From the Front Line". 18(3) International Criminal Justice Review, 2008, pp. 323-324.

67 Ibid., pp. 334-336. 
agentes estatais que participam das ações de prevenção e persecução do tráfico de pessoas é fundamental para o alcance dos resultados esperados. Por isso, é necessário investir nas dinâmicas organizacionais que podem revelar pautas de ação não alinhadas às políticas públicas em questão, como é o caso do enfrentamento ao tráfico.

Ainda são escassos os estudos sobre os processos decisórios das organizações envolvidas na investigação e na persecução penal do tráfico de pessoas. As pesquisas existentes sugerem que a repressão ao tráfico continua sendo um desafio e depende de ações institucionais integradas, a fim de que a prática seja redefinida como prioridade na área penal, o que supõe a construção de protocolos internos (premissa finalística) e de interações organizacionais a fim de contornar eventuais divergências nas estratégias de atuação ${ }^{68}$.

\section{O Controle Penal do Tráfico de Seres Humanos no Brasil}

No Brasil, o marco legal é o Código Penal de $1940^{69}$. Inicialmente, foi utilizada a expressão tráfico de mulheres ${ }^{70}$, circunscrevendo a vítima desse crime apenas a pessoas do sexo feminino. Há de se notar também que a questão foi inserida no Título Dos Crimes contra os Costumes, como era nominado até 2009. A solução é criticada, pois, “embora esteja presente a tutela da liberdade sexual e do pudor individual, prevalece a tutela do pudor público"71.

A Lei no 11.106, de 28 de março de 2005, alterou o Capítulo V para Do Lenocínio e do Tráfico de Pessoas, e pas-

68 FARRELL, Amy, OWENS, Colleen \& McDEVITT, Jack. "New laws but few cases: understanding the challenges to the investigation and prosecution of human trafficking cases". 61 Crime Law Social Change (2014), p. 143.

69 Ver Código Penal, Capítulo V, arts. 231 e 231-A. O Código Criminal de 1830 e o Código Penal de 1890 não abordaram a temática do tráfico de pessoas.

70 Ver Capítulo V - Do Lenocínio e do Tráfico de Mulheres. Código Penal - versão original.

71 CASTILHO, Ela Wiecko V. De. "A legislação penal brasileira sobre tráfico de pessoas e imigração ilegal/irregular frente aos Protocolos Adicionais à Convenção de Palermo", apresentação realizada no I Seminário Luso Brasileiro sobre Tráfico de Pessoas e Imigração Ilegal/irregular, em Cascais, Portugal, 22 a 24 de maio de 2006. Informativo PFDC no 43/2006. Brasília: Ministério Público Federal, Procuradoria Federal dos Direitos do Cidadão, 2006. Disponível em: http://6ccr.pgr.mpf.mp.br/pfdc/informacao-e-comunicacao/informativos-pfdc/edicoes-de-2006/maio-2006/. Acessado em $1^{\circ}$ de maio de 2016. sou a contemplar de forma mais adequada a proteção das vítimas do tráfico de seres humanos, independente do sexo. Além disso, a referida lei inovou ao inserir a modalidade de tráfico interno de pessoas ao ordenamento jurídico brasileiro, bastando o deslocamento dentro do território nacional para configurar a conduta criminosa. Essa alteração é bastante relevante em países com dimensões continentais, como o Brasil.

Em 2009, houve mais uma alteração no título do referido capítulo, por meio da Lei $\mathrm{n}^{\circ} 12.015$, passando a vigorar a expressão Do Lenocinio e do Tráfico de Pessoa para fim de Prostituição ou Outra Forma de Exploração Sexual. Contudo, a nova redação não abarca as diversas formas de exploração a que as vítimas de tráfico podem ser submetidas, como o tráfico de órgãos, o trabalho forçado, a mendicância forçada, entre outras. Os artigos 231 e 231-A do Código Penal criminalizam a conduta daquele que promove ou facilita o deslocamento de uma vítima, dentro ou fora do país, para prostituir-se ou ser explorada sexualmente. Algumas situações de vulnerabilidade foram previstas como causa de aumento de pena, como os casos em que a vítima é menor de idade, deficiente mental e em que há a participação de familiar, empregador ou pessoa responsável pelo cuidado da vítima. Se o crime for cometido com finalidade econômica, também deve ser aplicada multa ao infrator.

No Código Penal, outros tipos penais criminalizam a exploração das vítimas. No que tange à exploração do trabalho, o artigo 149 do Código Penal determina que é crime reduzir alguém a condição análoga à de escravo, submetendo a pessoa a trabalhos forçados, à jornada exaustiva, a condições degradantes de trabalho ou restringindo sua locomoção em razão de dívida contraída. Além disso, o aliciamento de trabalhadores, mediante fraude, a fim de levá-los para outra localidade, seja dentro ou fora do país, é crime previsto nos artigos 206 e 207 do Código $^{72}$.

O artigo 245 do Código Penal pune quem entrega filho menor de 18 anos, expondo-o a perigo, a fim de

72 É importante destacar que esse tipo penal corresponde ao contrabando (ou tráfico) de migrantes é previsto pelo Protocolo Adicional à Convenção das Nações Unidas contra o Crime Organizado Transnacional, relativo ao Combate ao Tráfico de Migrantes por Via Terrestre, Marítima e Aérea. Diferente do tráfico de pessoas, que é objeto da presente pesquisa, o contrabando de migrantes visa promover a entrada de migrantes em um país de que não é nacional ou residente permanente, não alçando a dimensão da exploração contida no tráfico de pessoas. 
obter lucro ou para envio ao exterior. É punido também aquele que auxilia o envio de menor para o exterior com o fito de obter lucro. Entre as leis esparsas, o artigo 239 do Estatuto da Criança e do Adolescente - ECA criminalizou a promoção ou o envio de menores para o exterior sem observar as formalidades legais previstas ou visando o lucro, independente da finalidade. O Estatuto também proíbe expressamente a submissão de criança ou adolescente à prostituição ou à exploração sexual, conforme artigo 244-A. Outras formas de exploração são condenadas de forma isolada, mas sem correlação direta com o tráfico. Critica-se que a "fragmentação do tratamento do tráfico de pessoas dificulta a compreensão do problema e conduz a distorções, principalmente no que se refere à quantidade da pena cominada" ${ }^{\text {"73 }}$.

A Lei $\mathrm{n}^{\circ}$ 9.434, de 4 de fevereiro de 1997, que dispõe sobre remoção de órgãos, tecidos e partes do corpo humano para fins de transplante e tratamento, criminaliza a compra ou venda de tecidos, órgãos ou partes do corpo humano, bem como a promoção, a intermediação, a facilitação ou obtenção qualquer vantagem com a transação.

Dadas as características próprias do tráfico internacional de pessoas, de formação de redes criminosas, é importante tratar da Lei $\mathrm{n}^{\circ} 12.850$, de 2 de agosto de 2013, que define organização criminosa como a associação de quatro ou mais pessoas, organizadas com base na divisão de tarefas, e que tenham o objetivo de obter vantagem de qualquer natureza, mediante a prática de infrações penais cujas penas máximas sejam superiores a quatro anos ou que sejam de caráter transnacional. Este conceito é aplicável também às infrações penais previstas em tratado ou convenção internacional, em que a execução e a consumação do crime ocorram em diferentes países.

Da forma como se apresenta hoje a legislação brasileira, não é possível afirmar que a criminalização do tráfico de seres humanos está adequada aos termos do Protocolo de Palermo. O capítulo que trata de tráfico de pessoas no atual Código Penal restringe-se à exploração sexual e à prostituição, sendo insuficiente, pois restringe o alcance do controle penal do tráfico de pessoas.

O I Plano Nacional de Enfrentamento do Tráfico de

73 BECHARA, Fábio Ramazzini, "Análise crítica do Projeto de Lei 2.845/2003”, In SECRETARIA NACIONAL DE JUSTIÇA, Tráfico de Pessoas: uma abordagem para os direitos humanos. Brasília: Ministério da Justiça, 2013, p. 202.
Pessoas - I PNETP ${ }^{74}$ previa metas de aperfeiçoamento da legislação brasileira sobre o tema, contudo pouco se evoluiu na vigência do Plano. Também no bojo do I PNETP, foram incluídas metas visando fomentar a cooperação entre os órgãos das diferentes esferas do Estado, a fim de promover a atuação articulada na repressão do tráfico de pessoas e na responsabilização dos infratores. Para isso, mostrou-se necessário criar e aprimorar instrumentos para o enfrentamento ao tráfico de pessoas, estruturar órgãos responsáveis pela repressão e fomentar a cooperação internacional.

O Relatório do I PNETP 75 aponta o alcance de diversas metas, entre elas, a realização de 22 operações especiais da Polícia Federal relacionadas ao tráfico internacional de pessoas para a prostituição. Dados da Polícia Federal revelam que, entre janeiro de 2010 e março de 2015, 347 inquéritos foram abertos para investigar o tráfico interno e internacional de pessoas apenas para fins de exploração sexual ${ }^{76}$. Segundo dados do Ministério Público Federal, houve 211 condenações por tráfico de pessoas no Brasil, no período de 2002 a $2008^{77}$. Esses dados não correspondem à totalidade das ações, uma vez que os sistemas informáticos não estavam implantados em todos os estados e ainda não permitem a extração de informações precisas sobre a atuação do sistema de justiça. Tampouco são bases confiáveis, pois não disponibilizam dados sobre os casos de tráfico de pessoas existentes no Brasil, em parte porque os sistemas não são interligados.

De forma geral, a falta de informação sistematizada e padronizada sobre o tráfico de pessoas e a subnotificação de casos são problemas apontados por diversas pesquisas $^{78}$. Consequentemente há grande dificuldade

74 BRASIL, Decreto no 6.347, de 8 de janeiro de 2008. I Plano Nacional de Enfrentamento do Tráfico de Pessoas - I PNETP.

75 MINISTÉRIO DA JUSTIÇA, Enfrentamento do Tráfico de Pessoas Relatório do Plano Nacional. Brasília, 2010, 257p. Disponível em http://www.justica.gov.br/sua-protecao/trafico-de-pessoas/politica-brasileira/anexos/2010relatoriopnet.pdf. Acessado em $1^{\circ}$ de maio de 2016.

76 CNJ - Conselho Nacional de Justiça, "PF investigou 374 casos de tráfico de pessoas para exploração sexual desde 2010", 30/03/2015. Disponível em http://www.cnj.jus.br/noticias/ cnj/78934-pf-investigou-374-casos-de-trafico-de-pessoas-para-exploracao-sexual-desde-2010. Acessado em 11 de junho de 2016. 77 MINISTÉRIO DA JUSTIÇA (2010), op. cit., p. 174.

78 MINISTÉRIO DA JUSTIÇA, Enfrentamento do Tráfico de Pessoas Relatório do Plano Nacional. Brasília, 2010, 257p. Disponível em http:// www.justica.gov.br/sua-protecao/trafico-de-pessoas/politica-brasileira/anexos/2010relatoriopnet.pdf. Acessado em $1^{\circ}$ de maio de 2016. SACCO, Andrea Cirineo, Trafficking in human beings for the pur- 
de se definir o perfil da vítima, o tipo de crime a ser combatido e a política pública mais adequada ao enfrentamento do tráfico de pessoas.

Em pesquisa sobre os procedimentos judiciais e extrajudiciais do MPT e MPF relativos ao tráfico de pessoas e ao trabalho escravo no estado de São Paulo ${ }^{79}$, verificou-se que "as classificações utilizadas tanto pelos Ministérios Públicos como pelo Judiciário não estavam claras e nem padronizadas, não havendo unicidade procedimental nem conceitual" " "[O] levantamento e sistematização de dados não faz parte da cultura organizacional, tanto de órgãos públicos quanto de organizações não governamentais envolvidas com a temática de enfrentamento ao tráfico de pessoas e trabalho escravo" ${ }^{\text {. }}$. A dificuldade de acesso à informação sobre o número de processos e condenações relativas ao tráfico de seres humanos foi detectada por Sacco em pesquisa na década de $2000^{82}$.

$\mathrm{Na}$ referida pesquisa sobre o tema, apontou-se para a necessidade de o Brasil desenvolver uma política de informação do sistema criminal de justiça, com a implementação de uma base de dados consistente e abrangente que permita que políticas de enfrentamento ao tráfico de pessoas sejam estabelecidas a partir de bases sólidas $^{83}$. A autora verificou, por exemplo, que as informações estatísticas da Polícia Federal até 2006 apresentavam apenas os casos de tráfico de pessoas "em

pose of sexual exploitation and corruption in Brazil: an in-depth analysis of the link between two criminal phenomena. Università Cattolica del Sacro Cuore, XIX ciclo, a.a. 2006/07, Milano, p. 128. RODRIGUES, Thaís de C., O tráfico internacional de pessoas para fim de exploração sexual e a questão do consentimento. Dissertação apresentada ao Programa de Pós-Graduação Stricto Sensu da Faculdade de Direito da Universidade de São Paulo, São Paulo, 2012, 150p. REPÓRTER BRASIL, UNODC e SECRETARIA NACIONAL DE JUSTIÇA, Tráfico de Pessoas em Pauta: Guia para jornalistas com referências e informações sobre enfrentamento ao tráfico de pessoas. São Paulo, 2014, pp. 31-33. RIBEIRO, Anália Beliza, "Por que é importante compreender o enfrentamento ao tráfico de pessoas como uma política de estado?", In: SECRETARIA NACIONAL DE JUSTIÇA, Tráfico de Pessoas: uma abordagem para os direitos humanos. Brasília: Ministério da Justiça, 2013, p. 173.

79 SÃO PAULO. Governo do Estado. Secretaria da Justiça e da Defesa da Cidadania. Secretaria de Gestão Pública. Tráfico de pessoas e trabalho escravo no estado de São Paulo: análise dos procedimentos judiciais e extrajudiciais do MPT e MPF. São Paulo, SJDC/ SGP, 2015, 95p.

$80 \quad$ Ibid., p. 67.

81 Ibid., p. 72.

82 SACCO, op. cit., p. 128.

83 SACCO, Andrea Cirineo, Trafficking in buman beings for the purpose of sexual exploitation and corruption in Brazil: an in-depth analysis of the link between two criminal phenomena. Università Cattolica del Sacro Cuore, XIX ciclo, a.a. 2006/07, Milano, pp. 47, 101-102, 122, 131 132. investigação", não estando disponíveis os casos "concluídos" nem as notícias de crime que não estavam sob investigação ${ }^{84}$. Além disso, identificou-se que não existe o registro sistematizado e coordenado de diferentes tipos criminais que possam estar diretamente ligados ao tráfico (como a falsificação de documentos).

O estudo mostrou que grande parte dos respondentes do questionário aplicado pela pesquisadora indicou “não ser capaz de responder" às questões sobre tráfico de pessoas e corrupção ${ }^{85}$. Para a autora, o dado mostra que "os agentes da justiça criminal no Brasil não estão conscientes da importância do problema ou são indiferentes, demonstrando a fragilidade do sistema de justiça criminal em geral" ${ }^{\prime \prime}$. A pesquisa demonstrou também que existe a percepção entre os respondentes do questionário de que o sistema de justiça criminal, em geral, fracassa ao investigar, processar e condenar agentes públicos e traficantes envolvidos no tráfico de pessoas e exploração sexual. ${ }^{87}$

Essa percepção é corroborada pelos dados apresentados pelo relatório elaborado pelo Conselho Nacional do Ministério Público - CNMP, em 2014. De todos os documentos classificados (inquérito policial; peça de informação; notícia de fato e processos judiciais), $24 \%$ foram judicializados ${ }^{88}$. No referido relatório, constam apenas dois registros do tipo "Execução de Pena". ${ }^{89}$ Já no relatório elaborado pelo Ministério Público de São Paulo, em apenas três casos foi possível identificar a condenação dos acusados, o que corresponde a $2 \%$ dos processos analisados ${ }^{90}$.

\section{Ibid., pp. 61-62.}

85 Participaram da pesquisa 109 pessoas. Os questionários considerados válidos foram respondidos por 59 promotores criminais, 10 policiais federais, dois membros de instituições governamentais, um especialista de Organização Não-Governamental e um juiz. SACCO, Andrea Cirineo, Trafficking in human beings for the purpose of sexual exploitation and corruption in Brazil: an in-depth analysis of the link between two criminal phenomena. Università Cattolica del Sacro Cuore, XIX ciclo, a.a. 2006/07, Milano, pp. 93-94.

86 Ibid., p. 104.

87 Ibid., p. 122.

88 No referido relatório, foram considerados apenas os seguintes tipos penais: Redução à condição análoga a de escravo (art. 149 CP); Aliciamento para ns de emigração (art. 206 CP); Tráfico internacional de pessoa para fim de exploração sexual (art. $231 \mathrm{CP}$ ); Tráfico internacional de pessoas (art. $231 \mathrm{CP}$ ); Tráfico interno de pessoa para fim de exploração sexual (art. 231-A CP); Tráfico interno de pessoas (art. 231-A CP); Entrega de filho menor a pessoa inidônea (art. 245 $\mathrm{CP}$ ); Promover ou auxiliar o envio de criança ou adolescente para o exterior (art. 239 e $\int$ único da Lei 8069/90).

89 CNMP - Conselho Nacional do Ministério Público, Levantamento sobre o Tráfico de Pessoas CNMP. Brasília: CNMP, 2014, 17p.

90 SÃO PAULO. Governo do Estado. Secretaria da Justiça e da 
Uma dificuldade identificada por pesquisa qualitativa sobre as representações sociais dos profissionais do direito é a dificuldade de articulação entre as diferentes organizações que atuam no enfrentamento ao tráfico de seres humanos ${ }^{91}$. Apesar de a autora identificar como fundamental o diálogo entre os gestores, ela detectou nas falas dos entrevistados a percepção de "descontinuidade e desarticulação da política de enfrentamento ao tráfico de pessoas, apontadas como fatores que dificultam a efetividade da política" ${ }^{\prime 2}$. Os sujeitos da pesquisa apontam a falta de comprometimento institucional com o tema, a troca constante dos gestores responsáveis pela pasta, a falta de articulação entre os diferentes órgãos como problemas constantes. Um deles ilustra a falta de comunicação inter-organizacional ao afirmar que "a PC [Polícia Civil] não sabe o que a Defensoria Estadual faz. E a Defensoria Pública Federal não sabe o que o Ministério Público faz (P7) "93. Para outro entrevistado, "não [se] consegue trabalhar com criminalidade organizada sem união de esforços e cooperação nacional e internacional" $" 94$.

A falta de cooperação entre os diferentes atores que participam do combate ao tráfico de seres humanos é apontada também no II Plano Nacional de Enfrentamento ao Tráfico de Pessoas - II PNETP, em que se identificou a necessidade de fomentar e fortalecer a cooperação entre órgãos públicos, organizações da sociedade civil e organismos internacionais no Brasil e no exterior ${ }^{95}$. $\mathrm{O}$ intercâmbio de informações, a atuação em

Defesa da Cidadania. Secretaria de Gestão Pública. Tráfico de pessoas e trabalho escravo no estado de São Paulo: análise dos procedimentos judiciais e extrajudiciais do MPT e MPF. São Paulo: SJDC/ SGP, 2015, p. 21.

91 Na pesquisa, "foram entrevistados oito profissionais do Direito, sendo três advogados, um juiz, um delegado da Polícia Civil, dois promotores de justiça e um defensor público da União. Todos os profissionais atuam em seus cargos há pelo menos 10 anos. Todos os entrevistados participam ou participaram em algum momento da Política de Enfrentamento ao Tráfico de Pessoas no Estado de São Paulo, como membros do Comitê de Enfrentamento ao Tráfico de Pessoas do Estado de São Paulo. Os advogados participaram como representantes de Organizações Não Governamentais e os demais entrevistados como representantes das Instituições às quais estão vinculados". FRINHANI, Fernanda de Magalhães Dias. As Representações Sociais dos Profissionais do Direito sobre Tráfico de Pessoas. Tese de Doutorado apresentada ao Programa de Pós-graduação em Direito da Faculdade de Direito da Universidade de São Paulo. São Paulo: 2014, pp. 82-83.

92 Ibid., p. 162.

93 Ibid., p. 165.

94 Ibid., pp. 175-176.

95 BRASIL, Portaria Interministerial $\mathrm{n}^{\circ} 634$, de 25 de fevereiro de 2013, II Plano Nacional de Enfrentamento ao Tráfico de Pessoas. rede e a atuação conjunta entre as diversas organizações podem ampliar a efetividade das ações de prevenção e repressão do tráfico de pessoas. ${ }^{96} \mathrm{O}$ II PNETP teve início em 2013 e a avaliação sobre o progresso do Plano indica a boa execução das ações propostas, com poucos pontos de atenção ${ }^{97}$. O Plano será executado até o final de 2016, quando deve ser elaborado novo relatório.

\section{Considerações finais}

O tráfico de pessoas tem se revelado prática altamente adaptável aos interesses de diferentes grupos sociais e ao espaço globalizado. Se, no começo do século $\mathrm{XX}$, o tráfico de seres humanos estava associado à prostituição, atualmente relaciona-se a outros fins, como a retirada de órgãos, a adoção ilegal e o casamento forçado. A evolução histórica do regime internacional que trata sobre a criminalização do tráfico de seres humanos evidencia que o tema é complexo, permeado por preconceitos que dificultam o aprimoramento legislativo. O foco da agenda internacional contemporânea deveria ser a proteção da vítima e o aperfeiçoamento de mecanismos de responsabilização dos agentes, inclusive por meio da intervenção penal.

A partir das ferramentas teóricas (categorias) utilizadas na presente análise pode-se destacar aquelas que propiciam potencial para o nosso enfoque ${ }^{98}$. Inicialmente, os programas condicionais, ponto de partida do enfoque organizacional-sistêmico. A pesquisa aponta para a necessidade de que os ordenamentos jurídicos dos

96 Sobre o assunto, o relatório do estado de São Paulo ressalta: "Também é fundamental aos Ministérios Públicos, assim como aos demais atores envolvidos na temática, que exista constante troca e difusão de informações, além da sistemática cooperação para formulação de ações estratégicas conjuntas que vão ao encontro das diretrizes do II Plano Nacional de Enfrentamento ao Tráfico de Pessoas e do II Plano Nacional para Erradicação do Trabalho Escravo". SÃO PAULO. Governo do Estado. Secretaria da Justiça e da Defesa da Cidadania. Secretaria de Gestão Pública. Tráfico de pessoas e trabalho escravo no estado de São Paulo: análise dos procedimentos judiciais e extrajudiciais do MPT e MPF. São Paulo: SJDC/SGP, 2015 , p. 67

97 MINISTÉRIO DA JUSTIÇA \& UNODC, Avaliação sobre o progresso do II Plano Nacional de Enfrentamento ao Tráfico de Pessoas. Disponível em https://www.unodc.org/lpo-brazil/pt/frontpage/2015/01/secretaria-nacional-de-justica-avalia-ii-plano-nacional-de-enfrentamento-ao-trafico-de-pessoas.html. Acessado em 10 de maio de 2016.

98 MACHADO, Bruno. Justiça criminal: diferenciação funcional, interaçoes organizacionais e decisões. São Paulo: Marcial Pons, 2014. 
Estados se ajustem às diretrizes internacionais e construam conceitos reciprocamente inteligíveis (se não unívocos), em conformidade com o caráter transnacional das práticas criminalizadas (criminalização primária). A literatura indica que a harmonização dos sistemas jurídicos internos aos parâmetros acordados internacionalmente é pressuposto para viabilizar a cooperação efetiva entre os Estados e tornar possível a investigação e a persecução penal de grupos criminosos que atuam além das fronteiras.

O segundo nível de análise remete tanto aos programas finalísticos (prioridades e estratégias) quanto à cultura organizacional, consistente nas rotinas cognitivas que estabilizam os processos decisórios em relação ao tráfico de pessoas. A pesquisa indica que o tema nem sempre é alçado ao status de prioridade organizacional, sendo preterido nos processos decisórios de diferentes organizações que participam da divisão do trabalho jurídico-penal. As divergências decisórias da Polícia e do Ministério Público em relação à incidência penal, assim como as construções jurídicas que afastam o tráfico de pessoas por distintas razões, inclusive estratégias (probabilidade de condenação), são relevantes para a compreensão sobre a forma como atuam algumas dessas organizações.

Um último dispositivo teórico é relevante nesta análise: as interações organizacionais. Dado que as organizações orientam-se de forma autorreferente e autopoiética, as interações organizacionais (intra e inter) podem viabilizar processos decisórios articulados e minimamente harmônicos ${ }^{99}$. Se o tema é pertinente para a análise da atuação em relação à criminalidade tradicional, ganha especial relevância quando associado à criminalidade transnacional, que remete a um rol extenso de organizações, as quais estão inseridas em diferentes realidades e contextos nacionais e internacionais.

Uma das dimensões relevantes das interações organizacionais deve ser direcionada para análise da cooperação internacional. Por meio da cooperação internacional, é possível se estabelecer pontos de contato entre organizações de diferentes países a fim de permitir o intercâmbio de informações e a efetivação de medidas

99 SEIDL, David. Organization and Interaction. In: SEIDL, David; BECKER, Kai Helge (Ed.). Niklas Luhmann and Organizational Studies. Kristianstad: Kristianstad Boktruyckeri AB, 2005. MACHADO, Bruno. Justiça criminal: diferenciação funcional, interações organizacionais e decisões. São Paulo: Marcial Pons, 2014. processuais em diferentes países, em conformidade com princípio da soberania estatal. A cooperação entre os diversos atores e organizações é imprescindível para a produção de provas, o rastreamento de recursos auferidos com o crime e a extradição ou a execução de sentença estrangeira. As medidas são necessárias para viabilizar a identificação das redes criminosas e a responsabilização dos traficantes. A cooperação internacional é fundamental para viabilizar a persecução penal e a punição dos agentes envolvidos. Para que a cooperação internacional seja eficaz, é importante também que haja o alinhamento entre os diversos atores que operam no enfrentamento do tráfico de pessoas. A troca de informações entre organizações, a consolidação de bancos de dados sobre o perfil da vítima, as formas de exploração e de atuação das redes criminosas atuaria a favor de um controle penal mais efetivo.

Os dados indicam que a realidade brasileira apresenta-se distante da considerada ideal. A legislação nacional ainda não se ajustou ao Protocolo de Palermo e as informações produzidas pelos diversos órgãos não são padronizadas. O Código Penal criminaliza apenas o tráfico de pessoas para exploração sexual. Outras formas de exploração foram definidas em legislações esparsas, sem conexão direta com o tráfico. Além disso, critica-se a falta de interação entre as organizações que participam da divisão do trabalho jurídico-penal em relação ao tráfico de pessoas. A construção de unidades especializadas e a criação de estratégias transnacionais, inspiradas pelo ideário de governança e de redes, poderiam ampliar e tornar mais eficaz a intervenção penal, a fim de institucionalizar mecanismos de comunicação e consolidar padrões unificados de atuação. A medida poderia superar incoerências e lacunas na implantação das estratégias definidas.

\section{REFERÊNCIAS BIBLIOGRÁFICAS}

ANITUA, Gabriel Ignácio. História dos Pensamentos Criminológicos. Trad. Sérgio Lamarão. Rio de Janeiro: REVAN, 2007.

ANJOS, F.A. dos e ABRÃO, P., "Enfrentamento ao Tráfico de Pessoas no Brasil: perspectivas e desafios". In ANJOS, F.A. dos et al., Tráfico de pessoas: uma abordagem para direitos humanos. Brasília: Secretaria Nacional de Justiça, Ministério da Justiça, 2013, pp. 215-233. 
ARAÚJO, Nádia, "A importância da cooperação jurídica internacional para a atuação do estado brasileiro no plano interno e internacional". In: Ministério da Justiça - Secretaria Nacional de Justiça, DRCI (org.). Manual de Cooperação Jurídica Internacional e Recuperação de Ativos Matéria Penal. $4^{a}$ ed., v. 1, Brasília, 2013, pp. 27-44.

AROMAA, Kauko, "Trafficking in Human Beings: Uniform Definitions for Better Measuring and for Effective Counter-Measures", in SAVONA, Ernesto U. \& STEFANIZZI, Sonia (eds.). Measuring Human Trafficking Complexities And Pitfalls, New York: Springer - INPAC, 2007, pp. 13-26.

BECHARA, Fábio Ramazzini, "Análise crítica do Projeto de Lei 2.845/2003", In: SECRETARIA NACIONAL DE JUSTIÇA, Tráfico de Pessoas: uma abordagem para os direitos humanos. Brasilia: Ministério da Justiça, 2013, pp. 195-205.

BALES, Kevin, "What Predicts Human Trafficking?", 31(2) International Journal of Comparative and Applied Criminal Justice (2007), pp. 269-279.

BERGALLI, Roberto. "Control social y sistema penal". In: BERGALLI, Roberto. Control social punitivo. Sistema penal e instancias de aplicación (Policía, Jurisdicción y Cárcel). Barcelona: Bosch, 1996, pp. 1-5.

CAPELLER, Wanda. "La transnationalisation du champ penal: réflexions sur les mutations du crime et du contrôle". In: Droit et Société, n 35, 1997, pp. 61-78.

"Schengen: son impact sur les acteurs locaux du contrôle". In: Droit et Société, n ${ }^{\circ} 42-43,1999$, pp. 265285.

CARTER, David L. "International Organized Crime: Emerging Trends in Entrepreunerial Crime". In: RYAN, Patrick J., RUSH, George E. (eds.), Understanding Organized Crime in Global Perspective: A Reader. Thousands Oaks/London/New Delhi: Sage, 1997, pp. 131-148.

CARVAlHO, Salo de. "Teoria Agnóstica da Pena: Entre os supérfluos fins e a limitação do poder punitivo". In: CARVALHO, Salo de. Crítica à Execução Penal. Rio de Janeiro: Lumen Juris, 2007.

CASTILHO, Ela Wiecko V. de "A legislação penal brasileira sobre tráfico de pessoas e imigração ilegal/irregular frente aos Protocolos Adicionais à Convenção de Palermo", apresentação realizada no I Seminário Luso Brasileiro sobre Tráfico de Pessoas e Imigração Ilegal/irregular, em Cascais, Portugal, 22 a 24 de maio de
2006. Informativo PFDC no 43/2006. Brasília: Ministério Público Federal, Procuradoria Federal dos Direitos do Cidadão, 2006. Disponível em: http://6ccr.pgr.mpf. $\mathrm{mp} . \mathrm{br} / \mathrm{pfdc} /$ informacao-e-comunicacao/informativos-pfdc/edicoes-de-2006/maio-2006/. Acessado em $1^{\circ}$ de maio de 2016.

CHILEA, D. e ENACHE, A.G., "Nouvelles Formes de la Traite des Etres Humain”, 2(45) Curentul Juridic 2011, pp. 55-70.

CHO, Seo-Young, "Evaluating Policies Against Human Trafficking Worldwide: An Overview and Review of the 3P Index", 1(1) Journal of Human Trafficking (2015), 86-99.

DE ANGELIS, Francesco. Internazionalizzazione degli scambi economici ed illegalità: una sfida per l'armonizzazione delle procedure repressive. In: Questione Giustizia, ns. 3-4, 1992, pp. 640-650.

FARRELL, Amy, OWENS, Colleen e McDEVITT', Jack, "New laws but few cases: understanding the challenges to the investigation and prosecution of human trafficking cases". 61 Crime Law Social Change (2014), pp. 139-168.

FERREIRA, Luciano Vaz \& MOROSINI, Fábio Costa, "Transgovernamentalismo e Cooperação Jurídica Internacional no Brasil”, in BAPTISTA, Luiz Olavo (coord.), Direito Internacional Contemporâneo. Curitiba: Juruá, 2014, pp. 185-209.

FRINHANI, Fernanda de Magalhães Dias. As Representacõoes Sociais dos Profissionais do Direito sobre Tráfico de Pessoas. Tese de Doutorado apresentada ao Programa de Pós-graduação em Direito da Faculdade de Direito da Universidade de São Paulo. São Paulo, 2014, 207p.

GALLAGHER, Anne T., The International Law of Human Trafficking. New York: Cambridge University Press, 2010.

GALLAGHER, Anne T. \& HOLMES, P., "Developing an Effective Criminal Justice Response to Human Trafficking. Lessons From the Front Line". 18(3) International Criminal Justice Review, 2008, pp. 318-343.

HUSSEIN, Rihab A. "The existing tensions in the defining of human trafficking at a UK and international level: a critical overview", 39(2) International Journal of Comparative and Applied Criminal Justice (2015), pp. 129-138

KANGASPUNTA, Kristiina, Collecting Data on Human Trafficking: Availability, Reliability and Compara- 
bility of Trafficking Data. In SAVONA, Ernesto U. \& STEFANIZZI, Sonia (eds.). Measuring Human Trafficking Complexities And Pitfalls. New York: Springer - INPAC, pp. 27-36.

KOTISWARAN, Prabha, "Protocol at the Crossroads: Rethinking anti-trafficking law from an Indian labour law perspective", 4 Anti-Trafficking Review (2015), pp. 33-55.

MACHADO, Bruno. Ministério Público: organizações, representações e trajetórias. Curitiba: Juruá, 2007.

Discursos Criminológicos sobre o Crime e o Direito Penal: Comunicação e Diferenciação Funcional. Revista de Estudos Criminais, vol. 45, abr/jun 2012.

Justiça Criminal e Democracia I. Coleção "Direito, Transdisciplinaridade \& Pesquisas Sociojurídicas". São Paulo: Marcial Pons/ FESMPDFT, 2013.

Justiça criminal: diferenciação funcional, interações organizacionais e decisões. São Paulo: Marcial Pons, 2014.

Justiça Criminal e Democracia II. Coleção "Direito, Transdisciplinaridade \& Pesquisas Sociojurídicas". São Paulo: Marcial Pons/ FESMPDFT, 2015.

MACHADO, Gustavo Seferian Scheffer, Acesso à informação e tráfico de pessoas: considerações sobre a Metodologia Integrada de Coleta e Análise de Dados e Informações. s/1, Artigo 19 Brasil, 2015, pp. 13-19.

MATTHEWS, Roger. "O mito da punitividade revisitado". In: MACHADO, Bruno Amaral. Justiça Criminal e Democracia II. Coleção "Direito, Transdisciplinaridade \& Pesquisas Sociojurídicas". São Paulo: Marcial Pons/ FESMPDFT, 2015.

MELOSSI, Dario. El Estado del control social. México/ DF: Siglo veintiuno, 1992.

PERLINGEIRO, Ricardo, "Cooperação Jurídica Internacional" in O Direito Internacional Contemporâneo, org. Carmen Tibúrcio e Luís Roberto Barroso, Rio de Janeiro, Renovar, 2006. Apud ARAUJO, Nádia, "A importância da cooperação jurídica internacional para a atuação do estado brasileiro no plano interno e internacional”. In: Ministério da Justiça - Secretaria Nacional de Justiça, DRCI (org.). Manual de Cooperaşão Jurídica Internacional e Recuperação de Ativos - Matéria Penal. 4a ed., v. 1, 2013, pp. 39-50.

PIRES, A. "Racionalidade penal moderna, o público e os direitos humanos na modernidade tardia". Revista Novos Estudos do CEBRAP, no 68, 2004, pp. 39-60.
PIPER, Nicola. "A Problem by a Different Name? A Review of Research on Trafficking in South-East Asia and Oceania", vol. 43 (1/2) International Migration (2005), pp. 203-233.

PUNCH, Maurice. "Bandit Banks: Financial Services and Organized Crimes". In: RYAN, Patrick e J. RUSH, George E. (eds.). Understanding Organized Crime in Global Perspective: A Reader. Thousands Oaks/London/New Delhi: Sage, 1997, pp. 115-130.

REPÓRTER BRASIL, UNODC \& SECRETARIA NACIONAL DE JUSTIÇA, Tráfico de Pessoas em Pauta: Guia para jornalistas com referências e informações sobre enfrentamento ao tráfico de pessoas. São Paulo, 2014, pp. 31-33. Disponível em http://www.justica.gov.br/sua-protecao/trafico-de-pessoas/publicacoes/anexos/traficode-pessoas-em-pauta-guia-para-jornalistas.pdf. Acessado em $1^{\circ}$ de maio de 2016.

RIBEIRO, Anália Beliza, "Por que é importante compreender o enfrentamento ao tráfico de pessoas como uma política de estado?”. In: SECRETARIA NACIONAL DE JUSTIÇA, Tráfico de Pessoas: uma abordagem para os direitos humanos. Brasília: Ministério da Justiça, 2013, pp. 155-176.

RODRIGUES, Thaís de C., O tráfico internacional de pessoas para fim de exploração sexual e a questão do consentimento. Dissertação apresentada ao Programa de PósGraduação Stricto Sensu da Faculdade de Direito da Universidade de São Paulo, São Paulo, 2012, 204p.

SACCO, Andrea Cirineo, Trafficking in buman beings for the purpose of sexual exploitation and corruption in Brazil: an in-depth analysis of the link between two criminal phenomena. Università Cattolica del Sacro Cuore, XIX ciclo, a.a. 2006/07, Milano, 169p. Disponível em http://tesionline.unicatt.it $/$ handle $/ 10280 / 206$ ? mode $=$ full\&submit_si mple $=$ Visualizza + tutti $+\mathrm{i}+$ metadat $\mathrm{i}+\mathrm{del}+$ documento. Acessado em 11 de junho de 2016.

SEIDL, David. Organization and Interaction. In: SEIDL, David; BECKER, Kai Helge (Ed.). Niklas Lubmann and Organizational Studies. Kristianstad: Kristianstad Boktruyckeri AB, 2005, pp. 145-170.

SILVA SÁNCHEZ, Jesus María. La expansión del derecho penal. Aspectos de la politica criminal en las sociedades postindustriales. $2^{a}$ ed. Madrid: Civitas, 2001.

SUZUKI, Natália, "Escravo, Nem Pensar! Uma experiência da sociedade civil para a prevenção ao tráfico de 
pessoas e ao trabalho escravo". In: SECRETARIA NACIONAL DE JUSTIÇA, Tráfico de Pessoas: uma abordagem para os direitos humanos. Brasília: Ministério da Justiça, 2013, p. 177-193.

UN.GIFT, "020 Workshop: Corruption and Human Trafficking: The Grease that Facilitates the Crime". The Vienna Forum to fight against Human Trafficking. Background Paper. Viena, 2008.

ZAFFARONI, Eugenio Raúl, et alli. Direito Penal Brasileiro. Rio de Janeiro: REVAN, 2011.

\section{Documentos e Relatórios Oficiais}

Acordo para a Repressão do Tráfico de Escravas Brancas (Convenção de 1904), disponível em https://treaties.un.org/ Pages $/$ ViewDetails.aspx? src $=$ TREATY\&mtdsg_ no=VII-8\&chapter=7\&lang=en. Acessado em 3 de abril de 2016.

BRASIL, Decreto n ${ }^{\circ} 4.377$, de 13 de setembro de 2002. Convenção sobre a Eliminação de Todas as Formas de Discriminação contra a Mulher (CEDAW).

BRASIL, Decreto n $\mathrm{n}^{\circ} 9.710$, de 21 de novembro de 1990. Convenção sobre os Direitos da Criança (CDC).

BRASIL, Decreto no 5.015, de 12 de março de 2004. Convenção das Nações Unidas contra o Crime Organizado Transnacional.

BRASIL, Decreto n 5.017, de 12 de março de 2004. Protocolo Adicional à Convenção das Nações Unidas contra o Crime Organizado Transnacional Relativo à Prevenção, Repressão e Punição do Tráfico de Pessoas, em Especial Mulheres e Crianças (Protocolo de Palermo).

BRASIL, Senado Federal, PLS 236/2012, Senado Federal. Consulta ao andamento: http://www25.senado.leg. br/web/atividade/materias/-/materia/106404. Acessado em $1^{\circ}$ de maio de 2016.

BRASIL, Senado Federal, PLS no 479/2012, Tramitação disponível em http://www25.senado.leg.br/web/ atividade/materias/-/materia/119888. Acessado em 5 de maio de 2016.

BRASIL, Decreto n ${ }^{\circ}$ 6.347, de 8 de janeiro de 2008. I Plano Nacional de Enfrentamento do Tráfico de Pessoas - I PNETP.

BRASIL, Portaria Interministerial no 634, de 25 de feve- reiro de 2013, II Plano Nacional de Enfrentamento ao Tráfico de Pessoas - II PNETP.

CNMP - Conselho Nacional do Ministério Público, Levantamento sobre o Tráfico de Pessoas CNMP. Brasília: CNMP, 2014, 17p.

Convenção Internacional para a Repressão do Trafico de Mulheres Brancas (Convenção de 1910), disponível em https://treaties.un.org/ Pages $/$ ViewDetails.aspx?src $=$ TREATY\&mtdsg no $=$ VII-9\&chapter $=7 \&$ lang $=$ en. Acessado em 3 de abril de 2016.

Convenção Internacional para a Supressão do Tráfico de Mulheres e Crianças (Convenção de 1921). Disponível em https://ec.europa.eu/anti-trafficking/legislation-andcase-law-international-legislation-united-nations/1921international-convention_en. Acessado em 3 de abril de 2016.

Convenção Internacional para a Supressão do Tráfico de Mulheres Maiores de Idade (Convenção de 1933). Disponível em https://treaties.un.org/Pages/ ViewDetails.aspx?src $=$ TREATY\&mtdsg_no $=$ VII$5 \&$ chapter=7\&lang=en. Acessado em 3 de abril de 2016.

Convenção para a Supressão do Tráfico de Pessoas e da Exploração da Prostituição de Outrem (Convenção de 1950). Disponível em https://treaties.un.org/Pages/ ViewDetails.aspx?src=IND\&mtdsg_no $=$ VII-11 a\&chapter $=7 \&$ lang $=$ en. Acessado em 3 de abril de 2016.

MINISTÉRIO DA JUSTIÇA, Enfrentamento do Tráfico de Pessoas Relatório do Plano Nacional. Brasília: MJ, 2010, 257p. Disponível em http://www.justica.gov.br/ sua-protecao/trafico-de-pessoas/politica-brasileira/ anexos/2010relatoriopnet.pdf. Acessado em 1o de maio de 2016.

MINISTÉRIO DA JUSTIÇA \& UNODC, Avaliação sobre o progresso do II Plano Nacional de Enfrentamento ao Tráfico de Pessoas. Brasília: MJ/UNODC, 2014. Disponível em https://www.unodc.org/lpo-brazil/pt/frontpage/2015/01/secretaria-nacional-de-justica-avalia-ii-plano-nacional-de-enfrentamento-ao-trafico-de-pessoas. html. Acessado em 10 de maio de 2016.

SÃO PAULO. Governo do Estado. Secretaria da Justiça e da Defesa da Cidadania. Secretaria de Gestão Pública. Tráfico de pessoas e trabalho escravo no estado de São Paulo: 
análise dos procedimentos judiciais e extrajudiciais do MPT e MPF. São Paulo: SJDC/SGP, 2015, 95p.

UNGA, A/RES/64/293, United Nations Global Plan of Action to Combat Trafficking in Persons, 12 August 2010, 12p.

UNODC, Global Report on Trafficking in Persons 2014. New York: UN Publication, 2014, 86p.

Global Report on Trafficking in Persons 2012. New

York: UN Publication, 2012, 98p.

\section{Notícias}

CNJ - Conselho Nacional de Justiça, "PF investigou 374 casos de tráfico de pessoas para exploração sexual desde 2010”, 30/03/2015. Disponível em http://www.cnj. jus.br/noticias/cnj/78934-pf-investigou-374-casos-detrafico-de-pessoas-para-exploracao-sexual-desde-2010. Acessado em 11 de junho de 2016. 
Para publicar na Revista de Direito Internacional, acesse o endereço eletrônico www.rdi.uniceub.br ou www.brazilianjournal.org.

Observe as normas de publicação, para facilitar e agilizar o trabalho de edição. 